\title{
Desempleo y servicio doméstico: el acceso al trabajo a través de la prensa de la ciudad de México (1805-1832)*
}

\section{Unemployment and Domestic Service: Access to Work Through the Mexico City Press (1805-1832)}

\author{
Francisco Javier Beltrán Abarca \\ (D) 0000-0002-5814-0132 \\ Universidad Nacional Autónoma de México, México \\ fra_yito3@hotmail.com
}

Resumen: Este artículo analiza el uso que los sirvientes domésticos hicieron de los periódicos de la ciudad de México para ofertar su fuerza de trabajo. Tomando como fuente los anuncios remitidos por amos y criados durante las tres primeras décadas del siglo XIX, el objetivo es demostrar que este mecanismo, alterno a las recomendaciones verbales, representó una vía socorrida para integrarse a un mercado laboral caracterizado por una sobreoferta de brazos dispuestos a ocuparse. Además de apreciar a un grupo de trabajadores que en su mayoría eran analfabetas, distinto de las elites letradas que la historiografía suele identificar como el principal público de los impresos, se ahonda en algunos aspectos que explican cómo se posicionaron frente al desempleo. Revisamos la manera en que se condujeron en la intermediación practicada por la prensa, así como sus preferencias en torno a la elección de un oficio que los ayudaría a obtener un medio de sustento.

Palabras clave: sirvientes; trabajadores; desempleo; anuncios; prensa.

* Agradezco la atenta lectura y sugerencias de los dictaminadores anónimos. Asimismo, a Alejandra Sánchez Archundia por comentar las primeras versiones de este texto. 
Abstract: This article analyzes the use domestic servants made of Mexico City newspapers to offer their labor. Using the announcements published by masters and servants during the first three decades of the 19th century as a source, the aim is to show that this mechanism, alternating with verbal recommendations, constituted a useful means of entering a labor market characterized by an oversupply of those willing to offer their services. In addition to highlighting a group of workers who were mostly illiterate, unlike the educated elites historiography usually identifies as the main consumers of printed matter, it explores certain aspects that explain how they positioned themselves in the event of unemployment. We review the way they behaved in the mediation practiced by the press, as well as their preferences regarding the choice of a trade that would enable them to secure a means of support.

Key words: servants; workers; unemployment; advertisements; press.

Fecha de recepción: 26 de noviembre de 2016 Fecha de aceptación: 8 de septiembre de 2017

$\mathrm{E}_{\mathrm{p}}^{\mathrm{s}}$ ste artículo analiza la manera en la que personas sin trabajo utilizaron la prensa de la ciudad de México con el ánimo de obtener un acomodo en el servicio doméstico. ${ }^{1}$ El objetivo principal es explicar cómo hicieron suyo el mecanismo de los anuncios para ofertar su mano de obra, y cómo se expresaron a través de ellos, lo que contribuye a entender, en última instancia, aspectos que dibujaron algunas cualidades del desempleo y las vías específicas para afrontarlo durante las primeras décadas del siglo XIX.

En aquel momento los sirvientes libres conformaban la segunda fuerza laboral más importante de la capital mexicana, sólo después de los artesanos,

${ }^{1}$ En el último apartado de este artículo se ahonda en los oficios que incluimos en este estudio como parte del servicio doméstico. Por ahora, sólo diremos que esta fue una forma de trabajo, retribuida con un salario -aunque no siempre-, enfocada al mantenimiento de los espacios domésticos y la asistencia a familias e individuos mediante la preparación de alimentos, hechura y aseo de ropa, así como trasportación de personas y cuidado de niños y enfermos. Asimismo, se hablará de sirvientes, criados o domésticos indistintamente, mientras que nos referiremos a los empleadores como amos, pues tales designaciones se encuentran frecuentemente en fuentes de diversa índole. Finalmente, sólo incluimos a los sirvientes libres, dejando fuera a los esclavos que se desempeñaron en esta ocupación. Es cierto que existieron anuncios sobre su comercio, pero estos reflejan la voluntad del amo-propietario por hacer uso de ese recurso, y no la de los trabajadores. 
cuyo número fluctuaba entre 10000 y 12 000, en una población que rondaba los 120000 habitantes (Pérez, 2004, pp. 58-59, 93 y 180; Salazar, 1987, pp. 7 y 43). Sin embargo, se sabe poco sobre la formación de ese mercado de trabajo en los dos primeros siglos del periodo colonial, pues estudios pioneros como los de Silvio Zavala (1987;1995) sobre el servicio personal de los indios apenas lo mencionan incidentalmente, sin examinar su complejidad. El avance actual de nuestro conocimiento al respecto ha provenido, en su mayoría, de un conjunto de investigaciones enfocadas al análisis de censos y padrones elaborados durante y después de la segunda mitad del siglo xviII. Entre las autoras que han reflexionado con profundidad el tema se encuentra Patricia Seed (1982), que con base en la muestra de un censo de 1753 estudia la correlación entre grupos ocupacionales y raciales presente en la ciudad. Uno de sus hallazgos es que el servicio doméstico atrajo a un alto porcentaje de hombres mulatos y de mujeres que pertenecían prácticamente a todas las calidades étnicas (pp. 583 y 586). Linda Arnold (1995), por su parte, retoma dos censos de 1777 y 1793, y a partir de una muestra perteneciente a algunas manzanas de la parroquia del Sagrario, concluye que entre un año y otro aumentó en esa zona el número de domésticos y de las familias que los empleaban (pp. 97 y 99). Otras investigaciones han abordado el tema a partir de perspectivas demográficas, aunque cada una con objetivos distintos. Flora Salazar (1987) lo estudia desde un enfoque de historia del trabajo, tomando como fuente el padrón de 1811, el mismo que, junto con otro de 1848, utiliza Silvia Arrom (1988) para tejer una historia de las mujeres y sus ocupaciones. Finalmente, Sonia Pérez Toledo (2004) se refiere a los sirvientes en el marco de un estudio integral de la estructura social de la ciudad, recurriendo a censos de 1790, 1811 y 1842 . Basados en padrones completos o sólo en algunas muestras, las aportaciones de estos trabajos no son menores. Han comprobado, entre otras cosas, que a mediados del siglo XVIII el mercado relacionado con el servicio doméstico no sólo era ya dinámico, sino que se expandió en las siguientes décadas por el crecimiento de la población. También han avanzado en el análisis de algunas variables como el género de los criados, edad, calidad étnica, patrones de migración y división del trabajo por oficios, las cuales permiten tener una idea de su conformación interna como grupo socioeconómico.

Con independencia tanto de la naturaleza de cada censo y padrón, como de la crítica de fuente a que cada autor los ha sometido al analizarlos, cabe subrayar que estos testimonios registran la actividad laboral que cada individuo declaró a los funcionarios encargados de levantar la información, 
pero no revelan si estaban ocupados, o si en realidad pasaban por una situación de desempleo, lo que no sería extraño, pues en el cambio de siglo existía una sobreoferta de brazos que no siempre encontró un acomodo con facilidad. Este subregistro de los índices de desocupación presente en los censos que no fueron diseñados para conocer a la población trabajadora "activa" y "pasiva" ha sido advertido por Carmen Sarasúa (1994), quien además apunta que las categorías y clasificaciones profesionales que esos documentos manejan tienden a velar o ignorar algunas formas de trabajo temporal, no asalariado, por horas, infantil, el realizado en casa, e incluso el femenino, rasgos a menudo presentes en el servicio doméstico. La autora nos recuerda que es común que los historiadores, bajo una "idea preconcebida de lo que debe ser la organización del trabajo en una ciudad", supriman aquellas modalidades de empleo, al considerarlas ambiguas o inestables, en aras de facilitar la construcción de categorías ocupacionales, lo que nos aleja de una visión más fiel de la realidad laboral (pp. 7-11).

Dado lo anterior, para apreciar ese mercado desde un ángulo diferente, a partir del cual sea viable explorar el fenómeno del desempleo, resultado de la relación entre la demanda y la oferta de brazos, utilizaremos una fuente complementaria a los censos, que consiste en los anuncios o avisos de oferta y demanda de sirvientes incluidos en los periódicos, como lo ha propuesto Sarasúa para el caso de Madrid de los siglos XVIII y XIX. Estos registros escritos, que aparecieron por primera vez en la ciudad de México en 1805, permiten identificar la actuación de los individuos cuando se encontraron sin una fuente de subsistencia, lo que a menudo es difícil de rastrear, ya que para acceder a un oficio la mayoría utilizó recomendaciones verbales asentadas en lazos de parentesco y amistad, además de que no contaron con organizaciones destinadas a ese propósito, a la manera de los gremios artesanales. Investigaciones sobre la historia del trabajo han mencionado su difusión a mediados del siglo xIX, pero además de que les prestaron poca importancia, no se dieron cuenta de que para entonces su publicación y circulación se encontraba disminuida en comparación con los inicios del siglo (Ruiz, 1979; Salazar, 1987). Otras menciones poco profundas se encuentran en la historiografía sobre la prensa y el periodismo (Becerril, 2015, p. 364; Delgado, 2006, pp. 32-33; Martínez Domínguez, 2010, p. 58; Martínez Luna, 2002, p. XxxiI).

La información de los avisos presenta alcances y limitaciones que conviene hacer explícitos para tener en mente qué nos pueden decir acerca de los sirvientes. Estos son géneros discursivos cortos en su extensión; constan 
de una a cuatro líneas y aparecían en la última de las cuatro páginas que integraban los diarios. Uno de sus principales sesgos es que dan cuenta de un universo acotado de trabajadores, que excluye a los individuos ya empleados y a los que accedieron a un oficio utilizando sólo recomendaciones orales. No obstante, aunque se trata de un segmento del servicio doméstico, estos testimonios poseen huellas que nos posibilitan una aproximación a un mercado laboral en movimiento, afín a los que vendieron su fuerza de trabajo al margen de los circuitos de la cultura letrada, ya que cada uno representa la historia personal -fragmentada e incompleta, huelga decirlo- de un hombre o una mujer buscando ganarse la vida. Tal historia se compuso, entre otras formas de experiencia, de las preferencias que los trabajadores albergaron en torno al tipo de oficio en que aspiraban colocarse.

Así entonces, estos papeles nos informan de los oficios solicitados por cada anunciante, si estaba dispuesto a salir de la ciudad para su desempeño, y en algunas ocasiones su nombre y estado civil. En cambio, datos sobre el origen étnico y la edad son registrados esporádicamente, lo que impide incluirlos aquí como variables en el análisis de las demandas en su conjunto. Respecto a los lugares de residencia de los sirvientes, algunos hacen explícita la ubicación de sus viviendas, pero en muchos otros se da la dirección del punto que serviría de contacto entre aquel y el amo interesado en emplearlo, aunque sin especificar si ese jacal, cuarto de vecindad, casa o accesoria, era la del propio criado o la de un amigo o conocido. Esos sitios también consistieron en comercios de toda clase de productos (bodegones, tiendas, carnicerías, tocinerías, panaderías, chocolaterías, alcaicerías, estanquillos, carbonerías); talleres de diferentes manufacturas (carpinterías, coheterías, herrerías, platerías, zapaterías, sederías, sastrerías); espacios de recreación y venta de comida (baños, mesones, cafés, pulquerías, fondas, atolerías, neverías); espacios religiosos, educativos y de gobierno (conventos, hospitales, colegios, amigas, casas de funcionarios del ayuntamiento), o las imprentas, alacenas y librerías donde se producían y distribuían los periódicos. A pesar de que no podemos identificar con precisión en qué parte de la ciudad habitaban todos los anunciantes, las menciones de esos lugares dejan entrever contactos y redes que los sirvientes tejían, desplazándose por calles y barrios, con actores sociales de una amplia pluralidad de profesiones y oficios, pero por cuestión de espacio no es posible tratar aquí ese asunto con amplitud.

Por tanto, aunque aludiremos constantemente a ciertos rasgos modeladores de los diarios, el enfoque asumido tiene que ver con la historia del 
trabajo, no de la prensa; los actores principales en estas páginas son los sirvientes haciendo uso de la cultura escrita. La mediación de los periódicos nos interesa en la medida en que puede decirnos algo sobre los cauces que tomó la demanda de empleo en un contexto francamente adverso para las clases populares, pues los historiadores parecen estar de acuerdo en que durante las últimas décadas del siglo XVIII y las primeras del XIX sobrevino un deterioro en sus condiciones de vida, a raíz de crisis agrícolas, crecimiento de la población urbana y la consiguiente presión sobre el mercado de trabajo, además de estancamiento de salarios y constantes alzas de precios en productos de consumo cotidiano como el maíz, el trigo y la carne (Florescano, 1986, pp. 68-89; Moncada, 2013, 149-150 y 155-156; Pérez, 2011, pp. 51-53; Quiroz, 2005, pp. 235-242). Y ante esa crisis económica, algunas familias reconfiguraron sus núcleos domésticos, incorporando a más integrantes, a fin de poder solventar la subsistencia grupal e individual (Scardaville, 2004). De este modo, no sólo se pretende demostrar que los sirvientes mantuvieron contacto con la producción periodística y con quienes estaban detrás de ella, sino también, ante todo, que esa aproximación fue determinada por su deseo de encontrar una estrategia complementaria a las recomendaciones verbales para demandar trabajo. Y el hacerlo supuso elegir, entre un abanico de posibilidades, uno o varios oficios con los cuales poder incorporarse al mercado laboral y salir de una situación de desempleo.

Para alcanzar los objetivos, he dividido el trabajo en cinco apartados. En el primero se precisa la importancia que tenía para la utilidad pública la divulgación de avisos en torno al trabajo. El segundo construye un análisis cuantitativo de los hombres y mujeres que recurrieron al uso de anuncios, centrándose en los difundidos por el Diario de México y El Sol, al ser las dos publicaciones que tuvieron mayor poder de convocatoria. En ese sentido, se explican algunas razones de esa destacada afluencia en comparación con otros periódicos, y su desarrollo al paso de los años por el influjo de distintas coyunturas políticas. El tercero se centra en explorar las rutas que pudieron seguir los criados, a menudo iletrados, para hacerse de avisos escritos y remitirlos a las imprentas. Y una vez ahí, cómo fue la mediación de los directores de los periódicos, quienes además de recibirlos, llevaron a cabo un ejercicio de edición antes de divulgarlos. La cuarta y última examina cuáles fueron las preferencias que tuvieron los sirvientes al momento de solicitar un acomodo; es decir, qué oficios fueron los más demandados y por qué, así como su disposición para desplazarse a lugares fuera de la ciudad si los amos lo requerían. 


\section{TRABAJO Y PUBLICIDAD}

A fines del siglo xVIII el periódico ocupaba un lugar secundario dentro de la cultura impresa de Nueva España, en la que predominaban formatos como el libro, folletos, gacetillas y hojas volantes sin regularidad fija y existencia efímera, así como devocionarios, catecismos y obras religiosas de consumo popular. La Gazeta de México marcó un cambio al respecto, al ser el primer papel en imprimirse durante un periodo más o menos largo (1784-1809), primero quincenal y después semanalmente. Con el sello oficial y bajo el cuidado de Manuel Antonio Valdés, su contenido estuvo enfocado al funcionamiento del gobierno tanto del reino como del resto de la monarquía hispánica. Una de sus características a destacar aquí fue la difusión de anuncios remitidos por el público, con un costo de dos reales que, junto con las suscripciones y la venta de libros salidos de su imprenta, servían para financiar su emisión (Suárez, 2015). También conocidos como "encargos", divulgaban información en torno al comercio de una amplia variedad de mercancías, almonedas, bienes inmuebles, juicios, loterías, abasto de la ciudad, clases particulares de idiomas y primeras letras. Tal heterogeneidad perseguía, sin embargo, un mismo fin: la práctica de la publicidad como vía para procurar el bien común.

En los últimos años del periodo colonial, a diferencia de lo que sería más tarde en las sociedades llamadas de consumo, el acto de publicitar radicaba en comunicar al cuerpo social o público un hecho que se tenía por valioso porque contribuía a mantener la vida en comunidad. Publicar por medio de un papel impreso debía perseguir una utilidad centrada en brindar un servicio al vecindario encaminado a mejorar su bienestar material y espiritual. En la búsqueda de ese propósito los impresos no tenían que atentar contra la religión ni las buenas costumbres, base de la cohesión entre individuos y corporaciones; tampoco les correspondía promover la crítica, la controversia, ni la desobediencia al rey, de ahí que las autoridades mantuvieran bajo su control el uso de la imprenta. La publicidad, entonces, estaba ligada indisolublemente a la felicidad del cuerpo político, tornándose en un asunto de buen gobierno y policía (Álvarez, 1992, pp. 301-317; Lempérière, 2013, pp. 240-245 y 260-267). El vecindario, por su parte, conocía muy bien su sentido y lo reproducía día a día mediante la oralidad o la escritura: pregoneros divulgaban disposiciones de gobierno, comerciantes voceaban sus mercancías en plazas y mercados, sacerdotes informaban de fiestas y servicios religiosos; 
la población adhería a los muros mensajes escritos para vender un producto o localizar un objeto extraviado. En consecuencia, los "publicistas" no hicieron más que retomar esas prácticas y encauzarlas a los periódicos, aunque conservando sus aspiraciones en favor del bien común.

En esa búsqueda, sin embargo, la Gazeta tuvo limitaciones en función del público para quien escribía. Sus lectores pertenecían principalmente a círculos letrados: autoridades reales, burócratas, ministros religiosos, hombres con inversiones en el gran comercio, la minería y la agricultura. Su circulación entre las clases populares no fue una prioridad, se entiende así la ausencia en sus páginas, durante 25 años, de información y avisos encaminados a su bienestar directo, acorde a sus propias necesidades e intereses. En contraste, los fundadores del Diario de México, Carlos María de Bustamante y Jacobo de Villaurrutia, ${ }^{2}$ se empeñaron a partir de 1805 en beneficiar no sólo al público de la Gazeta, sino también a aquellos para quienes la pobreza era asunto de todos los días. Y lo lograron. Sabedores de que una preocupación constante de los menesterosos era el acceso a un modo de subsistencia, recibieron y publicaron sin costo alguno anuncios en los que ofertaban su mano de obra. ${ }^{3}$ En apariencia menor, la innovación de este mecanismo, que por cierto ya se conocía en Madrid desde mediados del siglo XVIII, ${ }^{4}$ contribuyó a que la utilidad del Diario favoreciera a todas las capas del cuerpo social, más allá de cualquier elemento de diferenciación basado en criterios raciales, privilegios o grados de riqueza.

La crisis política desencadenada en 1808 en la monarquía hispánica tras la invasión napoleónica a la península ibérica, lo mismo que la guerra de Independencia en Nueva España y la intermitente pero definitoria libertad de imprenta, modificaron la sustancia de buena parte de la producción im-

${ }^{2}$ En nuestro periodo de estudio las funciones de los directores, editores y redactores de los periódicos se encontraban empalmadas, sin que hubiera divisiones claras entre unos y otros, así que las usamos indistintamente. En el Diario de México lo fueron: Carlos María de Bustamante y Jacobo de Villaurrutia (octubre de 1805-1806), Juan Wenceslao Sánchez de la Barquera (1806-1811), José Ruiz Acosta (septiembre de 1811-diciembre de 1812), y Juan Wenceslao Sánchez de la Barquera (diciembre de 1812-enero de 1817). Véase Delgado (2006, pp. $35-39$ y 249$)$.

${ }_{3}^{3}$ Diario de México, 1 de octubre 1805, s. p.; Diario de México, 3 de junio 1811, p. 630.

${ }^{4}$ Carmen Sarasúa (1994) analiza el mercado de trabajo del servicio doméstico a través del Diario Noticioso, Curioso, Erudito y Comercial, Político y Económico, impreso semioficial, publicado en Madrid con diferentes nombres entre 1758 y 1825. De acuerdo con la autora, en su primer año un promedio de diez criados lo utilizaba cada día para solicitar trabajo (pp. 11-18). Como veremos, la afluencia de trabajadores fue más modesta en la prensa mexicana. 
presa. Debatir y polemizar, prácticas que hasta entonces inspiraban desconfianza por considerarse que atentaban contra la cohesión del cuerpo social, se convirtieron en motor central de periódicos y folletos. Ya no sólo informaban sobre el ejercicio del gobierno, también discutían los principios que lo articulaban y legitimaban; se dirigían al público para persuadirlo de asumir una postura de cara a ese agitado panorama. Fue así que la prioridad del Diario de México transitó de la utilidad pública, en el sentido en que se ha descrito, a la disputa política, lo que suponía la fractura del cuerpo social. Este giro editorial marcó a los periódicos que surgieron en los siguientes años, pero su politización no suprimió del todo su contribución al mejoramiento del bien común. Como veremos, este cambio impactó negativamente en la frecuencia de los anuncios relacionados con el servicio doméstico, pero su inserción no se desdibujó sino hasta entrada la década de 1830, cuando comenzaron a adquirir un alto valor comercial.

\section{LA DEMANDA DE TRABAJO: SU DIMENSIÓN Y FRECUENCIA}

Durante los once años que circuló el Diario de México la demanda de trabajo constituyó más de tres cuartas partes del total de avisos ligados al servicio doméstico. Recabamos un total de 939 anuncios, de los cuales 214 corresponden a amos (22.79\%) y 725 a criados $(77.20 \%)$, de estos últimos 397 ofrecen mano de obra femenina (54.75\%) y 328 masculina (45.24). La aparición de anuncios desde las primeras entregas de este impreso se debió en buena medida a la manera en que sus fundadores concibieron la relación entre aquel y los habitantes de la capital. Bustamante y Villaurrutia procuraron atraer tanto "al pobre como al rico", a un público de las más variadas profesiones y oficios, sin dejar fuera a los trabajadores. Para llevarlo a cabo no sólo divulgaron textos con temas de su interés, expuestos con un estilo sencillo, alejado de la formalidad propia de los círculos letrados, a veces incluso emulando la oralidad de las clases populares (Becerril, 2015, pp. 363-371), también crearon un canal especial que facilitara el envío de papeles para su publicación. ${ }^{5}$

${ }^{5}$ No existe certeza sobre el tiraje habitual del Diario, pero es probable que haya sido de alrededor de 400 ejemplares. En sus primeros años el costo de suscripción mensual para la ciudad de México era de catorce reales; para 1812 el precio era de once pesos por seis meses; la 
Establecieron así doce buzones, localizados en estancos de tabaco repartidos por la ciudad, en los que "habrá una caja cerrada con llave, en que se echarán por la abertura de arriba los avisos, noticias, o composiciones que se quiera publicar por medio del diario", los cuales se recogían todas las tardes para trasladarlos a la imprenta. ${ }^{6}$ Este mecanismo operó durante los últimos meses de 1805 y buena parte de 1806, periodo que coincide con los años en los que se pudo leer la mayor cantidad de avisos de sirvientes y amos en comparación con los posteriores, como se observa en la gráfica 1, lo que nos habla del impacto que tuvo entre ese segmento de la población. No está claro cuándo dejó de funcionar, pero es altamente probable que fue antes de 1807, según lo expresado por Bustamante:

Si hubiera habido libertad para escribir, se habrían presentado producciones muy exquisitas; pero carecíamos de ella de todo punto, hasta prohibir el gobierno que continuasen los buzones que habíamos puesto en los estanquillos de cigarros, para que por ellos se pudiesen remitir los artículos que no quisiesen suscribir por modestia sus autores, y que por no darse a conocer no se presentasen en la oficina de redacción (Cavo,1870, pp. 677-678; Delgado, 2006, p. 29).

Este testimonio parece indicar que el cese ocurrió mientras Bustamante era uno de los directores, cargo del que se separó en septiembre de 1806 (Delgado, 2006, p. 36). No conocemos más detalles, pero se colige que fue una medida de las autoridades para reforzar su monopolio sobre la imprenta con miras a restringir la proliferación de escritos que escaparan a la censura real, medida acaso impulsada por los detractores del Diario. ${ }^{7}$ Desde entonces

suscripción foránea era doce pesos más cara (Delgado, 2006, pp. pp. 41-43). Es decir, el costo mensual aproximado era de un peso y seis reales, lo que debió significar una fuerte inversión en caso de que los sirvientes quisieran adquirir el impreso, cuyos salarios en términos generales oscilaban entre dos y diez pesos mensuales, según el oficio.

${ }^{6}$ Diario de México, 1 de enero de 1805, s. p. Actualicé la ortografía de todas las citas.

${ }^{7}$ Los fundadores del Diario obtuvieron licencia real para publicarlo, bajo la condición de no incluir noticias de índole político-económicas, ya que en su carácter de órgano oficial la Gazeta de México cumplía con ese propósito y no se quería que rivalizaran entre sí. No obstante, al inicio sus adversarios políticos acusaron al Diario de publicar textos que manifestaban poca afección al gobierno, al punto de que fue censurado y cerrado en más de una ocasión. Uno de ellos fue Juan López Cancelada, editor de la Gazeta, quien ejerció presión ante el virrey José de Iturrigaray, a fines de 1805 e inicios de 1806, para que lo suspendiera, argumentando que publicaba noticias de la exclusividad de aquella. Asimismo, en 1808 acu- 


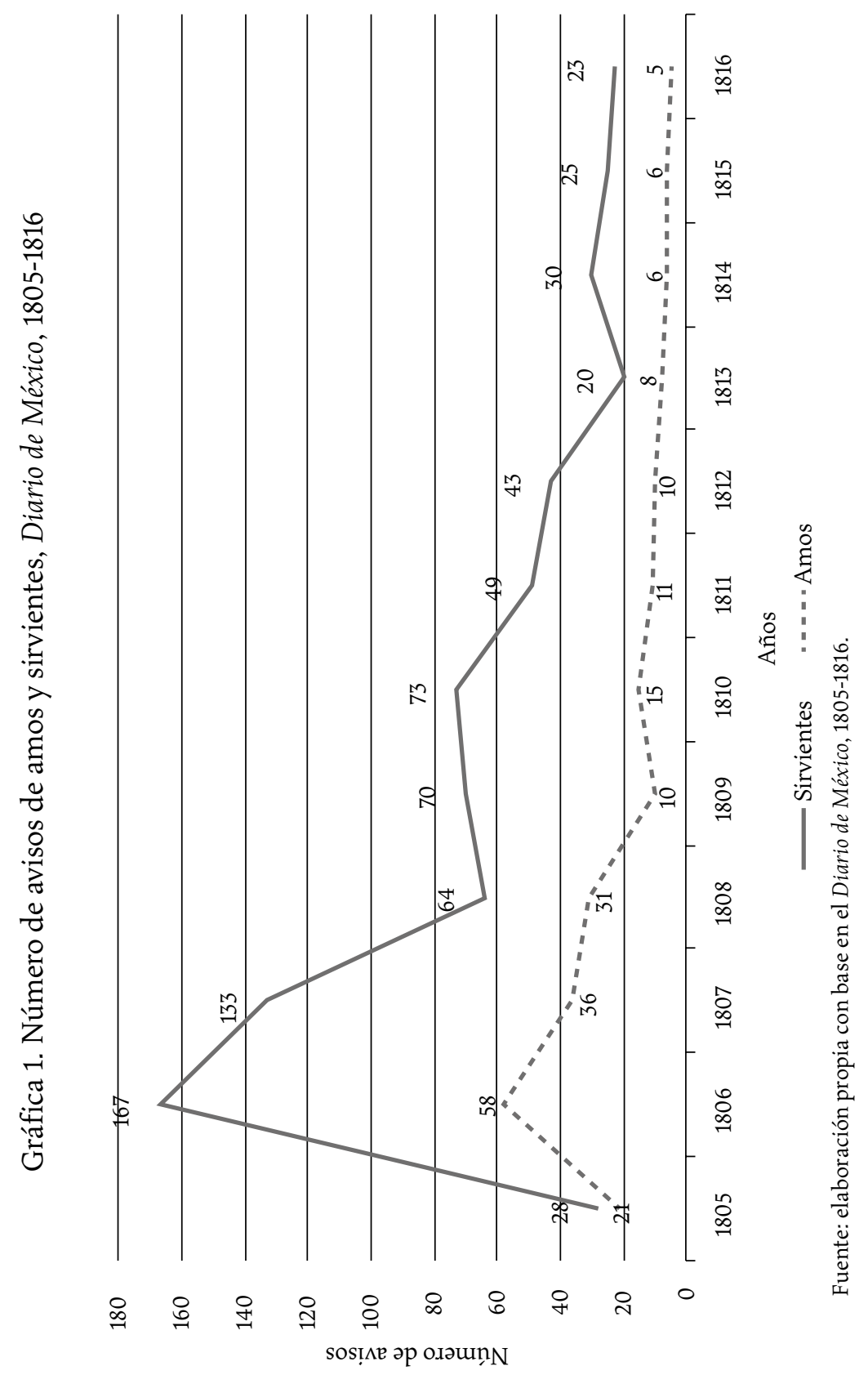


los papeles se enviaban directamente a la oficina e imprenta del periódico, lo que afectó sólo de forma parcial la cifra de anunciantes. Respecto al año anterior, en 1807 se presentó una disminución de 34 sirvientes y 22 amos. A partir de esto no es posible concluir que el reconocimiento del Diario como mediador había menguado, pues siguió siendo significativo el número de individuos que acudieron a él después de la desaparición de los buzones, aunque la situación cambiaría en los años que estaban por venir.

En 1808 la cantidad de criados experimentó una pronunciada caída de más de 50\%, ya que pasó de 133 en 1807 a 64 en aquel año. El hecho podría sugerir que perdieron interés en el diario, pero no hay motivos sólidos para creer que así fue, pues como lo demuestran las cifras los dos años previos, desde un inicio los trabajadores se apropiaron ese recurso dada su gratuidad y beneficios que potencialmente les reportaba, sin dejar de lado las recomendaciones verbales. En todo caso parece poco viable que una disminución tan drástica se haya debido sólo a una casualidad de las voluntades personales. Quizá la explicación se encuentra en los cambios que experimentó el canal de intermediación. La crisis imperial suscitada por la invasión napoleónica a la península marcó decisivamente al Diario, pues apenas llegaron a Nueva España las primeras noticias de la abdicación de Fernando VII su atención se dirigió en gran medida a informar y opinar sobre la guerra. Esta nueva postura editorial con un sesgo eminentemente político, que los directores no se habían atrevido a mostrar hasta entonces de modo franco y abierto, desatendió la publicación de avisos.

Si bien en 1809 y 1810 se registró un ligero ascenso, las cifras no volvieron a alcanzar los niveles de los primeros años, por el contrario, a partir de entonces mostraron un declive progresivo, como se aprecia en la gráfica 1. Esto cobra mayor significado si consideramos que la lucha armada entre las fuerzas insurgentes y realistas intensificó el traslado de familias tanto acaudaladas como pobres a la capital del reino, que huían de los estragos ocasionados en pueblos y ciudades aledaños, agravando el desempleo que ya existía, al grado que entre 1810 y 1813 las autoridades desplegaron un conjunto de medidas de policía para contrarrestar la proliferación de vagos y delincuentes, mantener el orden urbano y controlar los accesos a la ciudad (Ortiz, 1994). Pero ese movimiento migratorio no trajo aparejado un incremento proporcio-

só a Villaurrutia de usar al Diario para propugnar un gobierno autónomo y una junta local (Delgado, 2006, pp. 28-29 y 35-38). 
nal, o al menos un número sostenido de individuos ofertando o demandando trabajo en el servicio doméstico. La razón fue que las circunstancias políticas continuaron definiendo las prioridades del Diario, como queda de manifiesto por el amplio espacio que el director en turno dedicó para difundir las actividades de las Cortes Generales, por un lado, y la política contrainsurgente, con las que simpatizó, por otro. Durante esos años todos los avisos en general disminuyeron y la inserción de textos literarios, rasgo característico desde su fundación, pasó a un segundo plano (Martínez Luna, 2002, pp. XLIV$\mathrm{XLV})$. Cabe agregar que periódicos insurgentes como El Ilustrador Nacional (abril-mayo de 1812), El Ilustrador Americano (mayo de 1812-abril de 1813) y El Semanario Patriótico Americano (julio de 1812-enero de 1813) no difundieron avisos de ningún tipo, sin duda, debido a la propia naturaleza de sus objetivos y su impresión itinerante en medio del conflicto bélico.

En diciembre de 1812 dio inicio la segunda época del Diario. Juan Wenceslao Sánchez de la Barquera, en su calidad de director, expresó a sus lectores que los contenidos serían semejantes a los de la etapa precedente, lo que incluía textos de "economía política", literatura y avisos. ${ }^{8}$ En ese sentido, Susana Delgado (2006) sostiene que durante esta época el cotidiano tuvo una línea editorial más politizada, pero "la transformación no fue radical, sino parcial y paulatina", ya que no dejaron de insertarse "artículos sobre la vida cotidiana, versos, su sección de avisos" (pp. 10 y 38). La sistematización de estos últimos nos permite disentir y afirmar que al menos los relacionados con el servicio doméstico sí fueron claramente afectados, prueba de ello es que en 1813 se registró la cifra más crítica en toda la existencia del diario. Además, este ajuste en su línea editorial coincidió con un serio declive de sus fondos pecuniarios que amenazó su existencia, dada la escasez de suscripciones, fuente de su financiamiento. Y si bien el director hizo lo que estaba en sus manos para remediar la situación, ${ }^{9}$ las dificultades provocaron que su imprenta mudara de dirección en repetidas ocasiones, entorpeciendo la

${ }^{8}$ A inicios de 1812 el editor había comunicado al público que, fiel a la costumbre, continuaría insertando los remitidos "para que no decaiga" el cotidiano. Diario de México, 4 de enero de 1812, p. 16.

${ }^{9}$ En repetidas ocasiones el director conminó a los suscriptores a realizar sus pagos para evitar el cierre del cotidiano. En 1805 contaba con alrededor de quinientos suscriptores, pero a inicios de 1814 eran sólo menos de cien. Diario de México, 28 de junio de 1813, pp. 785-786; 30 de junio de 1813, p. 796; 23 de septiembre de 1813, p. 4; 31 de diciembre de 1813, p. 4; 1 de enero de 1814, p. 2; 4 de junio de 1814, p. 4. 
recepción de avisos, como lo manifestó en $1813 .^{10}$ Estas reubicaciones probablemente también afectaron el contacto de los vecinos con el despacho, dado que lo habían utilizado hasta entonces como espacio de intercambio de información en el que los interesados entraban en contacto para celebrar contratos laborales. ${ }^{11}$

Cuando en junio de 1814 se supo en la capital novohispana del restablecimiento de la monarquía y la derogación de las políticas liberales, entre ellas la libertad de imprenta, el Diario mostró entusiasmo por el retorno de Fernando VII, y cuestionó, antes elogiadas, la legitimidad de la Regencia, las Cortes Generales y la Constitución gaditana. Mientras tanto, el estado crítico de sus recursos empeoraba, haciendo insostenible cada vez más la empresa periodística, hasta que finalmente no hubo otra alternativa que cerrarla a comienzos de $1817 .{ }^{12}$ A manera de despedida, y tal vez evocando sus primeros años, en el último número el director recordaba a sus lectores la importancia que el diario tuvo tanto para los "sabios" como para el "bajo pueblo", que lo había utilizado para encontrar un acomodo, y concluía con un exhorto para que otros publicistas no dejaran de brindar ese servicio. ${ }^{13}$

La continuidad de esta práctica fue posible gracias al Noticioso General, único impreso que circuló durante un periodo prolongado una vez extinto el Diario de México, entre 1815 y $1823 .^{14}$ Aunque gran parte de su contenido estuvo enfocado a los temas del gobierno novohispano en sus últimos años y a la política trasatlántica de la corona española, también dio cabida a materias de corte misceláneo, ${ }^{15}$ y para ser "provechoso al común estar" y a la "utilidad pública”, desde su aparición se congratuló de recibir avisos sin costo alguno

10 Diario de México, 26 de diciembre de 1813, p. 4.

11 "Juan José Pérez, hombre solo, lo solicita de paje, portero, mozo de mandados, u otro semejante: ocúrrase al puesto del Diario del portal de Mercaderes, donde darán razón”, Diario de México, 15 de septiembre de 1810, p. 308; 22 de junio de 1806, p. 216; 12 de agosto de 1806 , p. 424; 2 de junio de 1807, p. 132; 27 de septiembre de 1808, p. 366; 29 de agosto de 1809, p. 250; 15 de junio de 1809, p. 682; 17 de julio de 1809, p. 68; 23 de agosto de 1810, p. 216; 21 de septiembre de 1810, p. 332; 3 de marzo de 1811, p. 248.

12 Diario de México, 3 de diciembre de 1816, pp. 3-4.

13 Diario de México, 4 de enero de 1817, p. 4. Citado en Delgado (2006, p. 34).

14 Virginia Guedea (2005) contabilizó un total de 101 publicaciones periódicas entre 1808 y 1821 . La mayoría se publicó durante la vigencia de la libertad de imprenta y tuvo corta duración pues sólo seis de ellos se publicaron entre seis y quince años.

${ }^{15}$ Al inicio tuvo una periodicidad irregular, hasta que a partir de diciembre de 1816 apareció tres veces a la semana. Sus temas de interés se agrupaban en cuatro apartados: 1) "avisos que pertenezcan a la utilidad común y personal”; 2) disposiciones del gobierno; 3) noticias po- 
en la imprenta de José María de Benavente. Es difícil saber con qué frecuencia se utilizaron por individuos sin acomodo, ya que no hemos localizado la colección completa de sus ejemplares que nos permita construir series numéricas. No obstante, pese a lo fragmentario y discontinuo de los números sueltos consultados, constatamos que difundió este tipo de avisos al menos en 1816,1819 y $1821 .{ }^{16}$ El intervalo entre cada uno de estos años nos hace pensar que los trabajadores mantuvieron un contacto permanente con esta publicación, quizá con altibajos, pero que no se extinguió pasadas las primeras entregas. En la antesala de la independencia hombres y mujeres desempleados conservaban, por un lado, la confianza en este mecanismo para integrarse al mercado laboral y, por otro, la capacidad de respuesta ante el surgimiento de nuevas publicaciones para cumplir con ese objetivo, lo que trascendería a los primeros años del republicanismo mexicano.

A mediados de 1825 estaba próximo a circular en la ciudad de México el Diario de Noticias o El amigo del Pueblo, cuyas páginas se dirigirían primordialmente a la "clase menos feliz, avisándola [de] lo que más le convenga", por lo que tendría muy claras sus preferencias editoriales:

De política será lo último de que hablaremos. Si nos hallamos con dos artículos comunicados, uno sobre el modo de hacer buen pan, y otro sobre el de hacer una buena Constitución, tomaremos el primero y dejaremos el segundo. Si uno tratase del establecimiento de una academia de ciencias y bellas artes, y otro de una asociación de vecinos, para cuidar de que el pueblo aprenda a ganarse la vida, elegiremos el segundo. ${ }^{17}$

En concordancia con este plan, otorgaba importancia capital a la difusión de avisos, pero lamentaba al mismo tiempo la ausencia de otros papeles enfocados a esa tarea, "pues hay cuatro periódicos de crédito, que se leen con interés y aun con placer; pero en su total están consagrados a esas materias que llaman políticas, económicas y de gobierno, que requieren otros lectores y otras necesidades: en ellos no podrían caber las menudencias y renglones

líticas de América y Europa, y 4) ciencias, artes, literatura, agricultura, comercio, impartición de justicia. Noticioso General, 24 de julio de 1815, pp. 1-2; 23 de diciembre de 1816, p. 4.

${ }^{16}$ Noticioso General, 19 de abril de 1816, p. 4; 19 de julio de 1816, p. 425 de octubre de 1819, p. 4; 15 de noviembre de 1819, p. 4; 21 de septiembre de 1821, p. 4; 22 de octubre de 1821, p. 4.

${ }^{17}$ El prospecto del Diario de Noticias se publicó en el Águila Mexicana, 14 de julio de 1825 , p. 1. 
que el hombre necesita para su vegetación, alojamiento, limpieza y comodidad". ${ }^{18}$ Con este breve pero certero balance el Diario de Noticias establecía cuál sería la singularidad de su contenido respecto al de otros periódicos, cuestión que radicaba en su manera de entender la noción de "pueblo", polisémica para esos momentos (Roldán, 2009). Según su visión, este consistía esencialmente en el conjunto de individuos que tenían vínculos con el mundo del trabajo, de quienes procuraría promover su bienestar material a través de dos vías: primera, con la exposición de "algunos pensamientos sobre la posibilidad de sacar de su abandono a la clase necesitada, y de establecer una comunicación entre ella y la clase afortunada", y segunda, dando cabida a la inserción gratuita de anuncios, sobre todo de sirvientes domésticos, menestrales y dependientes. ${ }^{19}$ No es dable ahondar, otra vez, en el impacto que ese diario tuvo entre las clases populares, puesto que únicamente se ha conservado su prospecto. Pero el proyecto periodístico en sí mismo es relevante, a pesar de que desconocemos si en efecto salió a la luz, la identidad de sus editores y la respuesta del público, porque fue uno de los pocos -el único, quizá - que en esa época tuvo el propósito deliberado de contribuir al mejoramiento de las condiciones de vida de los pobres, mediando entre estos y los grupos acaudalados en caso de ser necesario. ${ }^{20}$

Ahora bien, entre los "cuatro periódicos de crédito" aludidos por el Diario de Noticias estaba El Sol (1821-1832), que gozó de gran influencia pública en la década posterior a la independencia, y cuyo perfil editorial era ciertamente distinto del primero. Sus fundadores, Manuel de Codorniú, Eulogio de Villaurrutia, Manuel Fernández Aguado y Agustín Buenrostro, creían que su impreso ayudaría a "ilustrar al pueblo haciéndole conocer sus legítimos intereses para que sepa conservarlos, y establecer una opinión pú-

18 Águila Mexicana, 14 de julio de 1825, p. 1.

19 Águila Mexicana, 14 de julio de 1825, p. 1. A diferencia de otros periódicos que recibían avisos en sus propias oficinas e imprentas, el Diario de noticias lo haría en un "cajón" de la primera calle de Monterilla, una tienda de la esquina de Santa Catarina y la Encarnación y un "cuarto" de la calle de los Medinas.

${ }^{20}$ En la década de 1820 fueron pocos los hombres de letras que como José Joaquín Fernández de Lizardi apostaron por la instrucción de las clases populares, entre otras formas, mediante la divulgación de folletería y periódicos en gabinetes de lectura (Ozuna y Guzmán, 2001). Esa práctica tuvo lugar también en otros lugares de la ciudad. Uno de ellos fue un baño ubicado en el callejón de Betlemitas núm. 11, frecuentado por todas las clases sociales, en donde "se proporcionarán piezas decentes para que los Sres. concurrentes disfruten del trato social con la lectura de los papeles públicos que salen en esta capital". El Sol, 28 de octubre de 1824 , p. 544. 
blica capaz de contrarrestar a todas las tentativas de los enemigos de la felicidad pública". ${ }^{21}$ Más que con la clase trabajadora, su noción de pueblo estaba ligada a la idea del conjunto de individuos que conformaban el cuerpo social como entidad política, pero dividido por disputas heredadas de la crisis monárquica y la revolución de independencia. Después de la caída de Agustín de Iturbide, sus redactores se valieron de él para discutir con grupos de distinta filiación -borbonistas, iturbidistas, monarquistas y republicanos-el destino que tendría el país. ${ }^{22}$ Por ende, su pluma se encauzó sobre todo a las autoridades civiles y militares, agentes de la administración pública local y nacional, así como a ministros religiosos que eran actores clave en el juego político. ${ }^{23}$

Su inclinación por temas ideológicos y políticos sobre cualquier otro acotó los cauces, pero sin excluirlos por completo, para que los trabajadores en general, y los sirvientes en particular, se hicieran escuchar en sus páginas; acaso algunas veces se escribió en torno a ellos, pero casi siempre desde la visión del letrado o del amo. ${ }^{24}$ Bajo estas circunstancias los avisos de acomodo se convirtieron en un espacio de enunciación, modesto pero a fin de cuentas abierto a todo el público, de necesidades en las que estaba de por medio el sustento de algunas familias. Y es que durante la década de $1820 \mathrm{El} \mathrm{Sol} \mathrm{fue} \mathrm{el}$ impreso que convocó a más desempleados si se compara con otros de orientaciones políticas variadas, como el Águila Mexicana (1823-1828), la Gaceta Diaria de México (1825-1826), el Correo de la Federación Mexicana (1826-1829) y El Atleta (1829-1830). ${ }^{25}$ Entre 1823 y 1832 publicó 304 anuncios vinculados

${ }^{21}$ El Sol, 5 de diciembre de 1821, s. p.

22 Sobre la identidad de algunos redactores de El Sol, véase Martínez Domínguez (2010, pp. 39-51); sobre sus disputas con impresos como el Águila Mexicana o El Iris de Jalisco, véase Vázquez (2010, pp. 72-83).

${ }^{23}$ Cada número de El Sol costaba un real (Martínez Domínguez, 2010 p. 54), es decir, para comprarlo un mes entero se necesitaban casi cuatro pesos, monto no del todo accesible para los trabajadores, pues ello equivalía a la mitad o al salario completo de un sirviente.

${ }^{24}$ En un artículo titulado "Amos, criados" fomenta la relación paternalista entre uno y otro, así como los esfuerzos para disciplinar moralmente a los segundos. El Sol, 20 de mayo de 1828 , p. 7092.

${ }^{25}$ Además de El Sol, otro periódico influyente fue el Águila Mexicana, que si bien recibía anuncios para su posterior publicación (24 de julio de 1823), apenas localizamos catorce remitidos por sirvientes y tres por amos. Las cifras son inferiores en el caso de otras publicaciones, debido en parte a que tuvieron existencias más cortas, entre ellas el Correo de la Federación: tres sirvientes, cuatro amos; Gaceta Diaria de México: tres sirvientes, cuatro amos, y El Atleta: un sirviente. Aunque existieron otros papeles, aquí sólo aludimos a los de duración más extensa. 
al servicio doméstico, 265 eran de criados (87.17 \%) -141 ofertaban mano de obra masculina y 124 femenina-y 39 de amos (12.82\%), esto es, los primeros constituyeron más de cuatro quintas partes del total. Pero el acercamiento de estos trabajadores no fue uniforme durante ese periodo; se identifican tres cortes temporales: en el primero (1823-1825) se publicó sólo 9.05\% del total; el segundo (1826-1828) concentró 73.20\% y, finalmente, en el tercero (1829-1831) apareció $17.73 \%$ (véase gráfica 2 ).

El aumento paulatino de anunciantes posiblemente se benefició de ciertas mejoras en las condiciones materiales del periódico y de los talleres que lo producían. Entre 1821 y 1823 era bisemanario, a doble columna. Además de aumentar el tamaño de sus páginas, en 1824 se convirtió en diario, a tres columnas y con tipografía más pequeña, lo que supuso que los editores dispusieran de mayor espacio para incorporar contenidos. Por otro lado, su despacho estuvo localizado en direcciones más o menos estables después de 1823: en los bajos de San Agustín (julio de 1823-octubre de 1825) y en la calle de Capuchinas (octubre de 1825-diciembre de 1828), en donde "la mayor amplitud del local y hermoso surtido de caracteres nuevos" le permitió "seguir sirviendo al público con toda la exactitud que hasta ahora lo ha hecho y con mayor extensión". ${ }^{26}$ Este dato es relevante toda vez que, al igual que el Diario de México, esas instalaciones fueron identificadas al paso del tiempo por amos y criados no sólo para la entrega de avisos, ${ }^{27}$ también fungieron como sitios en donde los dependientes e impresores proporcionaban información a los vecinos sobre ofertas y demandas de empleo, incluidos aquellos que acudían directamente a la imprenta de Martín Rivera sin haber consultado antes el periódico. ${ }^{28}$

En 1828 las solicitudes de trabajo alcanzan su nivel más alto en toda la década, mientras que el número de ofrecimientos se contrae respecto a los

${ }^{26}$ El Sol, 27 de octubre de 1825, p. 4. "Para que los anuncios que se mandan a este periódico no padezcan retraso en su publicación y se verifique esta según el orden en que se reciben, sólo se insertarán los que se entreguen en la librería y despacho del Sol”, El Sol, 31 de diciembre de 1826, p. 2262.

${ }^{27} \mathrm{El} \mathrm{Sol}, 31$ de diciembre de 1826, p. 2262.

${ }^{28}$ El Sol, 6 de julio de 1823, p. 88; 25 de noviembre de 1824, p. 692; 2 de diciembre de 1824 , p. $720 ; 10$ de marzo de 1825, p. 1108; 7 de septiembre de 1825, p. 460; 4 de mayo de 1825, p. 1332; 17 de mayo de 1825, p. 1384; 7 de septiembre de 1825, p. 460; 1 de febrero de 1826, p. 932; 23 de febrero de 1826 , p. 1020; 15 de diciembre de 1826, p. 2198; 11 de mayo de 1827 , p. $2874 ; 12$ de abril de 1828, p. 6042; 9 de mayo de 1828, p. 7050; 16 de julio de 1829, p. 64; 14 de octubre de 1829, p. 424. 





dos años previos (véase gráfica 2). Es claro que este hecho no puede leerse como representativo de todo el mercado laboral relacionado con el servicio doméstico, aunque sí puede tomarse como indicativo de un excedente de mano de obra con dificultades para ser contratada. De hecho, en aquellos momentos el malestar social alcanzó a otros segmentos de la sociedad que experimentaban apuros para conservar sus medios de subsistencia o acceder a ellos, como fue el caso de los artesanos del ramo textil. ${ }^{29} \mathrm{Y}$ a finales de aquel año los sirvientes perdieron la oportunidad de valerse de ese mecanismo escrito, bajo un contexto de profunda polarización política.

No ahondaremos en los complejos acontecimientos de 1828, pues otros autores los han explicado con detenimiento. Basta mencionar que la elección presidencial de septiembre había dado una reñida victoria a Manuel Gómez Pedraza, vinculado a la logia escocesa y los "imparciales", resultado que fue desconocido por su opositor Vicente Guerrero y por varios miembros de la logia yorkina. Surgieron así pronunciamientos y conspiraciones en distintos puntos del país que impugnaban los comicios y apoyaban a este último. El camino de las movilizaciones armadas culminó en diciembre con la rebelión de la Acordada y saqueos al mercado del Parián y otros comercios de la ciudad de México, conmocionada en las semanas siguientes (Arrom, 2002). Los pronunciados alcanzaron su objetivo: Gómez Pedraza renunció, y Guerrero asumió la presidencia en abril de 1829. Como partidario del primero, El Sol dejó de publicarse en diciembre de 1828 , reapareciendo en julio de 1829 . Pero la crisis política ya había dejado sentir sus efectos, al interrumpir de golpe el despunte de anuncios y debilitar la función mediadora del periódico; es decir, lo distanció de los domésticos, impidiendo que se estrechara más su relación como había venido sucediendo.

Tras su reaparición, El Sol recrudeció el tono de sus críticas hacía el gobierno de Guerrero y sus ministros al considerarlo ilegítimo, lo que se agravó por un ambiente de descontento en torno a las facultades extraordinarias que el presidente había asumido durante los últimos meses, ratificadas por el Congreso, y que fueron vistas como atentados contra las soberanías estatales,

${ }^{29}$ Pérez (1996, pp. 112-113 y 164-165). En 1828, según Potash (1986, pp. 48-50), los artesanos textiles, unos de los más numerosos de la ciudad, fueron perjudicados por la falta de inversión en la producción manufacturera, así como por la desventaja que representaba la política económica de los primeros gobiernos republicanos que favorecía la introducción de mercancías extranjeras, gracias a los bajos aranceles establecidos en 1827, en detrimento de la producción interna. 
especialmente en materia fiscal y de libertad de imprenta (Ávila, 2008, pp. 91-93), Eso lo condujo a mostrar su apoyo al Plan de Jalapa en diciembre de 1829, que básicamente desconocía a Guerrero (Vázquez, 2010, pp. 201-202). Asumió entonces la presidencia Anastasio Bustamante, a quien este diario mostró su respaldo al debatir con otras publicaciones que le eran contrarias (Andrews, 2008, pp. 173-176). Esto sugiere que no tuvo desavenencias al menos con el poder ejecutivo que interfirieran en su actividad periodística. Los problemas surgieron, al parecer, dentro de su organización interna. Al mismo tiempo que su despacho se reubicó repetidamente, tuvieron lugar discrepancias entre sus redactores que se agudizaron al grado de que algunos optaron por abandonarlo, como Luis Antepara en junio de 1830, y otro más en $1831 .^{30}$

No hay certeza de si estas disputas incidieron en la caída de anuncios de sirvientes después de 1829. Si ocurrió así, es probable en todo caso que esa no fuera la única causa. Hay que tomar en cuenta que después de su reaparición El Sol continuó publicando de forma habitual su sección de avisos, lo que evidencia que su despacho se mantuvo abierto para que el público los remitiera, ¿por qué entonces lo hicieron sólo pocos trabajadores domésticos? No es sencillo explicarlo, pero podemos sugerir un elemento que quizá fue más decisivo que las pugnas internas: la desconfianza con la que El Sol comenzó a ver a las clases populares. Como recio opositor a la administración de Guerrero, un segmento de la elite política lo utilizó de vehículo para deplorar la intervención activa de la "plebe" en los motines de finales de 1828 (Di Tella, 1994, cap. 7; Warren, 2001, pp. 100-108). Esa animadversión hacia la participación política de los pobres, vistos como ignorantes y que sólo buscaban los puestos públicos para su beneficio personal, pronto permeó a otras instancias del poder, entre ellos el Congreso general, cuando algunos diputados propusieron reformas a la Constitución de 1824, con el beneplácito de este y otros periódicos, para establecer el voto censitario en favor de los propietarios (Andrews, 2006, pp. 80-82). No es posible descartar, por tanto, la hipótesis de que esta postura editorial condujo de algún modo al debilitamiento de la intermediación de El Sol, toda vez que su distanciamiento de las clases populares fue un acto intencionado de sus editores.

Las publicaciones sucesivas no tuvieron un papel destacado en la difusión de avisos sobre servicio doméstico. Durante la década de 1830 aparecie-

\footnotetext{
${ }^{30}$ La historiografía aún no ha podido aclarar la identidad de todos los directores, editores y redactores de El Sol después de su reaparición en 1829 (Martínez Domínguez, 2006, pp. 50-51).
} 
ron ocasionalmente en algunos periódicos, pero sin alcanzar cifras significativas, ${ }^{31}$ tendencia que se mantendría en los años cuarenta. Aunque algunos conservaron la gratuidad, ${ }^{32}$ el cobro por ese servicio se fue generalizando. El Monitor Republicano fijó en 1846 tarifas proporcionales según la riqueza del anunciante, siendo los pobres quienes menos pagaban, entre los que se contaban sirvientes y otros trabajadores que debían gastar dos reales por cada papel menor a ocho líneas; si rebasaba ese tamaño el costo se ajustaría según el aumento. ${ }^{33}$ El precio era ligeramente mayor en el caso de periódicos oficiales. ${ }^{34}$

Esta ausencia de sirvientes no fue casual. Resultó de una progresiva saturación de anuncios que daban paso al mercado de productos, trasladando a un plano secundario el mercado de trabajo y otras materias orientadas al bien común, como ocurría apenas unas décadas atrás. Ante el siempre fluctuante número de suscripciones, otrora fuente de financiamiento, directores e impresores encontraron en esta situación una vía más o menos estable para solventar los gastos de sus empresas editoriales, algunas veces con miras a su crecimiento, haciendo de los diarios una mercancía que reportaba ganancias (Pérez Salas, 2003, pp. 117, 120-121, 126-128). A la vez, este negocio requirió del aprovechamiento de las novedades en los procesos y técnicas de impresión para mejorar el diseño de los avisos: se tornaron grandes y detallados, las

${ }^{31}$ Así ocurrió en periódicos de influencia nacional y local como La Lima de Vulcano, 4 de junio de 1834 , p. 252; 16 de agosto de 1834, p. 188; 6 de noviembre de 1834, p. 346, 30 de diciembre de 1834, p. 440; así como en impresos oficiales, Diario del Gobierno de la República Mexicana, 15 de enero de 1837, p. 60; 22 de febrero de 1837, p. 212.

32 El Republicano (1846-1847), impreso por Ignacio Cumplido, no cobraba los "avisos de personas indigentes que soliciten destinarse". Pese a este beneficio, en sus páginas no se localizan anuncios vinculados a la oferta y demanda de trabajo en general.

${ }_{33}$ En relación con los pobres precisaba que "el gran número de personas desvalidas y sin más capital que su trabajo, que diariamente se hallan en el caso de ofrecerlo para procurarse su sustento, podrán insertarlos [...] a un precio más módico que los demás". Ese rubro incluía a criados y "operarios de artes y oficios", así como avisos "a favor de los indigentes", hospitales y casas de beneficencia. El Monitor Republicano, 29 de noviembre de 1846, p. 4. Hemos consultado los ejemplares de este periódico desde su fundación en 1846 hasta 1850, lo que nos ha permitido constatar que, a pesar de su importante influencia y circulación, el número de anuncios remitidos por domésticos y otro tipo de trabajadores fue escaso. Sobre sirvientes, véase El Monitor Republicano, 4 de octubre de 1846, p. 4; 13 de septiembre de 1848, p. 4.

${ }^{34}$ En 1839, el órgano del gobierno cobraba dos reales por anuncios entre una y cuatro líneas, cuatro reales de cinco a diez líneas, y 1.5 pesos los superiores a las diez líneas. Diario del Gobierno, 31 de marzo de 1839, p. 60. Algunos anuncios de sirvientes en Diario del Gobierno de la República Mexicana, 1 de enero de 1837, p. 4; 15 de enero de 1837, p. 60, 22 de febrero de 1837, p. 212. 
posibilidades tipográficas aumentaron, y aparecieron las primeras viñetas o ilustraciones pequeñas. Dentro de esta nueva lógica, en periódicos de gran trascendencia como El Siglo Diez y Nueve y El Monitor Republicano predominaron cuatro tipos de anunciantes que tenían en común la capacidad económica para costear ese servicio: medianos y grandes comerciantes, empresarios de espectáculos recreativos (teatro, ópera, corridas de toros), impresores que ofertaban sus propias producciones y, en menor medida, abogados, profesores y médicos que ofrecían al público sus servicios profesionales. Estos actores ya habían estado presentes desde inicios del siglo, lo particular fue que, a diferencia de los sirvientes, tuvieron la capacidad no sólo de adaptarse, sino de aprovechar para su propio beneficio estos cambios.

\section{REDACCIÓN, EDICIÓN Y LECTURA DE AVISOS}

La cifra de anuncios permite conocer el nivel de penetración que tuvieron entre los trabajadores, pero el dato cuantitativo dice poco de cómo se los apropiaron para incorporarse a los circuitos de la cultura escrita. La información disponible en los diarios no revela la manera en que los redactaron, pero es probable que los iletrados hayan recurrido a prácticas de intermediación. Así como Judith Kalman (2003) afirma que "el empleo de la lengua escrita en la sociedad nunca ha dependido de que la población fuera capaz de utilizarla en lo individual, sino sólo de su capacidad para responder a él y reconocer su valor, su uso y su autoridad" (p. 36), podemos decir, parafraseándola desde una perspectiva histórica, que a pesar de que la población urbana era en su mayoría analfabeta, los sirvientes domésticos no se mantuvieron impávidos ante una realidad en la que la escritura tuvo un papel cada vez más destacado en la mediación de las relaciones labores.

Algunas veces la redacción tuvo lugar en el propio círculo familiar de los criados, cuando solicitaron un acomodo simultáneamente a un pariente o amigo que sabía escribir, quien tal vez preparó el anuncio incluyendo la demanda de ambos. ${ }^{35}$ Otros encontraron ayuda en las calles. Registros fechados entre 1800 y 1840 hablan de la presencia de escribanos públicos o "evan-

\footnotetext{
35 "En el callejón del Padre Lecuna núm. 2 se dará razón de un escribiente, y una recamarera: ambos son hermanos de buena cuna y regular conducta", Diario de México, 16 de febrero de 1807, p. 186; también, 25 de marzo de 1807, p. 336.
} 
gelistas" en los portales de las Flores, de Mercaderes y junto al Parián, ${ }^{36}$ una de las zonas urbanas más concurridas por todos los estratos sociales dada su trascendencia comercial y política. Laboraban bajo condiciones modestas, moviéndose entre compradores y vendedores ambulantes, puesto que no estaban instalados en tiendas o escritorios fijos (Lyon, 1984, p. 210; Mayer, 1953, p. 61; Mühlenpfordt, 1993, p. 220; Sartorius, 1990, p. 19). Circulaban y de vez en vez se plantaban en las inmediaciones de las alacenas y despachos de donde salían los periódicos y se distribuían. Esta cercanía a los puntos que también servían para la remisión de avisos pudo incentivar un contacto asiduo entre clases populares y escribanos, toda vez que esa interacción ya se conocía desde el siglo XVIII, y por la cual Juan de Dios Arias (1974) afirmó a mediados del XIx que eran los "secretario[s] particular[es] del público que no sabe escribir" (p. 72).

Por lo general acudían hombres y mujeres pobres -con una destacada presencia de criados $-^{37}$ a solicitar escritos de los más variados géneros, cuyo costo oscilaba entre uno y dos reales, aunque había quien "regateaba": peticiones y quejas dirigidas a las autoridades, documentos contables y judiciales, cartas familiares, avisos sobre objetos o personas extraviadas, esquelas, felicitaciones, y papeles para solicitar un "empleo o emolumentos", entre otros (Arias, 1974, pp. 68-70; García 1986, pp. 226-229; Mayer, 1953, p. 61; Mühlenpfordt, 1993, p. 220). Los usuarios no tenían habilidades en lectoescritura o no manejaban el estilo y lenguaje que algunos papeles exigían según el destinatario y las circunstancias (los relacionados a litigios judiciales, por ejemplo), sin embargo, como lo ha demostrado con agudeza Kalman (2003), intervinieron de forma activa en la elaboración de sus propios escritos debido a la naturaleza del contacto que establecieron con el evangelista.

Los clientes los visitaban con una idea preconcebida, y no siempre acabada, de la clase de papel que necesitaban. Durante su interacción, ambos tomaban decisiones, implícita o explícitamente, en torno al contenido y tono; hicieron lecturas en voz alta, intercambiaron preguntas, redactaron en conjunto y añadieron correcciones. ${ }^{38} \mathrm{Su}$ comunicación verbal, que incluía la lectura de la gestualidad -componente esencial de la oralidad-, era interpretada

${ }^{36}$ Diario de México, 7 de julio de 1810, p. 26; González (1979, pp. 16 y 17); Brantz (1953, p. 6).

${ }^{37}$ Diario de México, 7 de julio de 1810, p. 26; Arias (1974; pp. 69-71); García (1986, 226-227).

${ }^{38}$ Existen varios testimonios que muestran este fenómeno. En la narración sobre el evangelista, escrita por Juan de Dios Arias (1974) para Los mexicanos pintados por sí mismos, una mujer acude al escritorio público para obtener una carta destinada a su esposo apenas 
y registrada por el escribano, orientando con ello la estructura formal ${ }^{39}$ y el tono del texto (lenguaje, ritmo e inflexiones), aspectos que, utilizados adecuadamente, podían granjearles una respuesta positiva por parte de los destinatarios (Dorra, 1997, pp. 14-29). ${ }^{40}$ De modo que el servicio de los escribanos públicos era posible gracias al entrecruzamiento entre escritura y oralidad.

Si bien los evangelistas contribuyeron en ciertos casos a sortear la desventaja que suponía el analfabetismo, en otros la comunicación verbal de los sirvientes se vio constreñida porque no hablaban el castellano. La pluralidad lingüística presente en la capital, nutrida en buena medida por la migración

liberado de la cárcel, quien en vez de buscarla, prefirió irse de la ciudad. Entonces tiene lugar el siguiente diálogo:

-“¿Le hablará vd. de tú?

-Sí Señor.

- ¿Cómo se llama?

-Señor, se llama José Cayo de la Cadena; pero le dicen por mal nombre Garfias.

-No le pongamos ese apodo porque se incomodará.

-No le hace, Señor, no le hace: yo quiero que la carta sea una cosa que le arda el alma: dígale vd. que no más me busca cuando lo ponen preso, para que yo lo mantenga; que si él no había de mantener siquiera a sus hijos para qué se casó.

-Bueno, señora, a ver qué le parece a vd.

Y el secretario ordenó lo mejor que pudo la redacción [...]". Mientras la mujer hablaba, el evangelista continuaba interactuando con ella: "El secretario meditó, escribió, y ella volvió a interrumpir añadiendo: dígale vd. que si se enoja a mí ni... y la cliente sin terminar la ira se levantó los hombros en ademán de desprecio haciendo lo que llaman un dengue: el escribiente debía, en mi concepto, hallarse embarazado para describir aquel dengue; pero el hombre que no se para en pintas, tradujo aquella frase muda poniendo -ni tantito me importa" (p. 68). Cursivas en el original. Otros ejemplos en García (1986, pp. 226-229).

${ }^{39}$ En el caso de la nota anterior, la mujer dicta lo que quiere que diga su carta e interrumpe repetidamente al evangelista para corregir o agregar elementos. Por su parte, este le sugiere no incluir el apodo y lee la gestualidad de la mujer, la interpreta y registra con sus propias palabras. Otro testimonio relata que "[el evangelista posee] gran talento para componer un texto comprensible y agradable a partir de los pensamientos e indicaciones más confusas y a menudo apenas balbuceadas" (Mühlenpfordt, 1993, p. 220).

${ }^{40}$ La mujer del diálogo, por ejemplo, mantuvo en su carta el apodo de su esposo para mostrarle su disgusto. Pero el escribano también tomó parte. Gracias a su experiencia en el manejo de la letra en beneficio de los demás, conocía muy bien qué tipo de escritura debía utilizarse en contextos específicos - "que estaba al tanto de todas las situaciones de la vida"-, qué palabras, fórmulas preestablecidas o tipo de papel usar según el receptor (Arias, 1974, p. 69). Otra fuente registra: "Alguna desconsolada damisela o alguna enamorada con el corazón desecho vacían su corazón con desahogos pasionales que el escriba traduce en la fraseología del caso [...]" (Mayer, 1953, p. 61). Cursivas mías. 
relacionada con el trabajo, era un fenómeno cotidiano (Villavicencio, 2010) (1 $^{41}$ del que formaron parte algunos anunciantes. Entre ellos había un "un indito de edad de trece años [que] busca casa en donde servir por una cosa corta por no saber hablar en castellano, solo en su idioma que llaman Cucateco [sic cuicateco]", ${ }^{42}$ perteneciente a las comunidades asentadas en la sierra norte del actual estado de Oaxaca (Mühlenpfordt, 1993, p. 172). Sin duda, este joven monolingüe no habría podido remitir su aviso sin el respaldo de otro individuo que poseyera algún grado de bilingüismo, quien registró su oralidad por medio de la escritura y la tradujo al idioma que predominaba en la cultura letrada. Posiblemente el mediador fue el portero de la casa a la que debían acudir los interesados y responsable de "entregar" al muchacho.

Otros actores clave que definieron las cualidades de la mediación periodística fueron los dependientes de las imprentas y los editores. Por un lado, algunas veces se entorpeció la recepción de avisos, como en 1811, cuando el responsable del Diario sospechó que sus empleados cometían el "exceso" de cobrar una tarifa no autorizada a los anunciantes, coartando la remisión de papeles. ${ }^{43}$ Por otro, debido a la preponderancia que se daba a noticias y opiniones de corte político y económico, algunos anuncios fueron abreviados ${ }^{44}$ lo que no siempre satisfizo a los trabajadores, ya que se dejaban fue-

${ }^{41}$ En la Plaza del Volador "la gritería de los ardientes mexicanos, los distintos idiomas de los indios, el regateo de compradores y vendedores produce tal ruido que podría pensarse que aquí se discute el bienestar del mundo" (Heller, 1987, pp. 145). Mühlenpfordt (1993) anotó: "Especialmente novedoso para mí eran los gritos de los vendedores en las calles -sobre todo en las primeras horas de la mañana- de verduras, frutas, pan, leche, atole y tamales, así como productos de la industria de los nativos. Los vendedores son en su mayoría aztecas y pregonan en su propia lengua, no en español, sus mercancías, de manera que únicamente los nativos de la ciudad de México entienden lo que ofrecen" (p. 220).

${ }^{42}$ Diario de México, 16 de diciembre de 1805, p. 338.

${ }^{43}$ Diario de México, 3 de junio de 1811, p. 630.

${ }^{44}$ La edición de los remitidos fue una práctica común. En 1825, el prospecto del Diario de Noticias indicaba que "entrados [los papeles] en nuestra jurisdicción serán decapitados, esto es, se les quitará la cabeza cuando se reduzca[n] a cumplidos, y elogios estériles, y todo lo que no tenga ninguna utilidad o gracia; pero no se suprimirá cosa importante en la sustancia o en el modo. El objeto es dar grano y no paja: lo útil y agradable", Águila Mexicana, 14 de julio de 1825, p. 2. Ejemplos de edición de los anuncios en el Diario de México, 21 de marzo de 1806, p. 320; 26 de marzo de 1806, pp. 340; 27 de octubre de 1806, p. 232; 10 de noviembre de 1806, p. 293; 13 de junio de 1808 , p. 562; 14 de junio de 1808, p. 566; 15 de octubre de 1811, p. 432; 28 de noviembre de 1811, p. 608. El Sol, 9 de octubre de 1825, p. 468; 11 de octubre de 1825, p. 476; 17 de agosto de 1826, p. 1718; 6 de septiembre de 1826, p. 1798. 
ra las condiciones bajo las cuales estaban dispuestos a laborar. ${ }^{45}$ Así ocurrió cuando el director del Diario recibió un papel firmado por "El hermano de la costurera", en el que expresaba su queja por haber editado el aviso de su pariente, causándole un perjuicio por no reconocer su experiencia laboral, pues "cualquier persona que de las cualidades de aquella costurera necesite, no entenderá que no lo es, porque no lo explica, y si hará desprecio, en el supuesto de que será una de muchas comunes costureras que hay". ${ }^{46}$

Uno de los asuntos más complicados de esclarecer para la historiografía ha sido el tipo de circulación y recepción que la prensa tuvo entre el público, especialmente en las clases populares, al suponerlas en mayor o menor medida iletradas y apartadas del consumo de impresos. Es cierto que en las primeras décadas del siglo xIX el público-lector estaba compuesto en su mayoría por individuos con habilidades en lectoescritura y con capital suficiente para pagar una suscripción o comprar números sueltos con cierta regularidad, condiciones de las que a menudo carecían los sirvientes. ¿Qué sentido tenía entonces la publicación de ofertas de trabajo si no sabían leer, no entendían a cabalidad su contenido o estaban alejados del mundo letrado? Quizá debamos prestar atención a un principio implícito en los avisos de los amos: durante años los remitieron porque confiaban en que, por una $u$ otra vía, llegarían al conocimiento de sus destinatarios últimos -los trabajadores-, de lo contrario no habría tenido sentido utilizar el periódico con ese propósito.

${ }^{45}$ El siguiente caso muestra un ejercicio de edición sutil, pero revelador, de las condiciones de trabajo anunciadas. "Si alguna persona de las que pasan a España en el próximo convoy quisiere llevar una niña en calidad de sirvienta, ocurra a la calle del Montón número 7." Pocos días después se publicó el mismo papel con un cambio: "Si alguna persona de las que pasan a España en el próximo convoy quisiere llevar una niña en calidad de sirvienta sin ganar ningún salario, ocurra a la calle del Montón número 1[sic] en la vivienda principal”, Diario de México, 11 y 13 de octubre de 1815, p. 4. Cursivas mías.

${ }^{46}$ El aviso había sido enviado en los siguientes términos: "Una persona lo solicita de costurera, en una casa donde haya niñas, o niños, pues a más de saber cortar y hacer túnicos, hace lo mismo de ropa de hombres: ocúrrase a la calle primera de $\mathrm{S}$. Francisco, núm. 12, entresuelo interior." Se publicó así: "Una persona lo solicita de costurera: ocúrrase [a la calle primera de S. Francisco, núm. 12, entresuelo interior]”, Diario de México, 20 de noviembre de 1811, p. 576. Otro ejemplo sobre la incorporación de información sobre la experiencia laboral del anunciante en Diario de México, 8 de marzo de 1807, p. 264. 
Según estimaciones basadas en censos, cerca de $80 \%$ de los domésticos de la ciudad de México eran mestizos e indígenas, ${ }^{47}$ sectores con alto índice de analfabetismo a finales del siglo XVIII ${ }^{48}$ situación que se confirma en los anuncios. Al cotejar los de sirvientes con aquellos que fueron remitidos por administradores de haciendas, dependientes de establecimientos comerciales, escribanos y profesores de primeras letras que también buscaban empleo, se advierte que si bien estos manejaban la letra y los números en grados y modos distintos entre sí, todos tenían en común la escritura como forma de subsistencia. ${ }^{49}$ Ese conocimiento les permitía aspirar a un trabajo mejor remunerado y con mayor reconocimiento social. De haber contado con él, los criados no habrían dejado pasar la oportunidad de expresarlo, como pocos lo hicieron, ${ }^{50}$ con el objetivo de hacerse de mejores condiciones laborales. En cambio, dijeron dominar saberes relacionados con diferentes oficios: "sabe bordar y labrar", "sabe lavar, planchar, guisar", "es inteligente en el oficio de cocinero", "Dolores Guerrero [...] solicita acomodarse o de costurera o de lavandera, advirtiendo que en lo primero está muy versada". ${ }^{51}$

Si bien la lectura en voz alta fue un conducto socorrido y eficiente para la difusión de impresos entre sectores analfabetos, podemos ir más allá y advertir la trascendencia que tuvieron los elementos estructurales de los anuncios para su divulgación. Conviene reconocer que el formato del periódico estaba compuesto por una variedad de géneros discursivos, y cada uno fue leído de distinta manera (Leyva, 2015, pp. 65-72). En contraste con los editoriales o artículos de opinión que definían y discutían apasionadamente términos e ideas en aras de articular un discurso para enunciar la realidad política (ciudadanía, división de poderes, representatividad, república,

${ }^{47}$ En 1790, en los cuarteles 1, 20 y 23 de la ciudad de México habitaban alrededor de 1514 individuos dedicados al servicio doméstico, de los cuales, 332 eran "blancos" (21.9\%), 576 "indígenas" (38\%) y 606 "castas" (40\%) (Pérez, 2004, p 16).

${ }^{48}$ Tanck (1999, pp. 443 y 445) calcula que en 1810 en la intendencia de México sólo 9.5\% de los indios hombres sabía leer, y quizá sólo la mitad de ellos también escribir.

${ }^{49}$ Diario de México, 7 de octubre de 1805, p. 28; 12 de enero de 1806, p. 44; 16 de febrero de 1806, 188; p. 28 de septiembre de 1812, p. 372; El Sol, 9 de marzo de 1825, p. 1108; 24 de enero de 1827 , p. 2358.

${ }_{50}$ "Un sujeto de buena conducta solicita destinarse de mozo o portero, muy útil para el servicio de casa: tiene una regular letra, y dará un buen papel de conocimiento: la persona que lo necesite, ocurra al puente del Espíritu Santo núm. 6, donde darán razón”, El Sol, 17 de noviembre de 1828, p. 7818.

${ }^{51}$ Diario de México, 2 de octubre de 1805, p. 8; 3 de febrero de 1806, p. 136; 4 de marzo de 1807 , p. 242; 15 de diciembre de 1814 , p. 4. 
constitucionalidad), la finalidad de los avisos era transmitir un mensaje de fácil comprensión a un amplio público, economizando palabras dado el poco espacio disponible en los diarios. Estos se vertebraban por expresiones que designaban una realidad palpable, no por abstracciones para construir conceptos. Entender su lenguaje no requería interpretaciones múltiples o análisis detenidos; sus enunciados eran claros porque remitían al mundo que los sirvientes conocían y habitaban: nombres de personas, direcciones o referencias geográficas de la ciudad, saberes, habilidades y oficios.

El pensamiento de los trabajadores se alimentaba de la experiencia material, y se recreaba por medio de la oralidad, sin depender necesariamente de la escritura; sus vivencias cobraban sentido en situaciones particulares y circunstanciales, no en definiciones o categorías analíticas (Ong, 1987, pp. $44,48,54$ y 60 ). Ello no significa que los avisos representen la oralidad, base de la comunicación practicada por los domésticos, pues esta se encuentra prácticamente reducida o nula. Lo que se quiere plantear aquí es que su estructura simple y lenguaje conciso hicieron posible no solamente que fueran leídos de manera textual por los trabajadores, después de una ojeada selectiva de los géneros que integraban el periódico, sino que también permitieron a una segunda persona reseñarlos a quienes no sabían leer; es decir, reconstruir su significado al poco tiempo de su publicación, incluso sin contar con el papel frente a sus ojos. Esta trasmisión de los contenidos parece plausible porque sin ser lectores habituales de los diarios, los iletrados no dejaron pasar la oportunidad de utilizarlos, según lo hemos visto.

\section{LA ELECCIÓN DE UN OFICIO Y UN LUGAR DE TRABAJO}

¿Cómo se posicionaron los sirvientes de cara al desempleo? ¿Qué dijeron sobre sus expectativas para incorporarse al mercado de trabajo? ¿Qué expresaron de sí mismos? Aunque la información de los anuncios es limitada para responder a estas preguntas, podemos comenzar por identificar de qué manera definieron los contornos de lo que entendían por servicio doméstico, pues la idea que el historiador tiene de este depende, en buena medida, de la clase de testimonio a través del cual lo mira. Así, por ejemplo, en las fuentes de índole jurídica, tal vez como en ninguna otra, es posible encontrar intentos explícitos, por parte del poder político, para determinar quiénes eran los 
sirvientes, a veces con el fin de regularlos o controlarlos, otras para evaluar la posibilidad de convertirlos en contribuyentes, o bien, para excluirlos de los derechos políticos. Esto último fue particularmente cierto en junio de 1821, a propósito de la formación de las juntas electorales de parroquia en Madrid, cuando se precisaron los alcances de la vaga mención que de ellos había hecho la Constitución de Cádiz con el fin de impedir su participación en los comicios:

bajo la referida voz [la de sirvientes domésticos] sólo deben comprenderse los criados que estipulen o contraten prestar a las personas de sus amos como objeto principal, algún servicio casero puramente mecánico con exclusión de otro cualquiera que pertenezca a las labores o ejercicio de campo, y de los relativos a las ciencias, artes, comercio, industria, educación de niños o jóvenes, desempeño de oficinas de cuenta y razón, y demás de iguales y semejantes clases, que de ninguna manera estén reputados por propios y peculiares de los criados domésticos (Dublán y Lozano, 1876, p. 545).

Es interesante que los anuncios, a pesar de que no esbozan ninguna definición tan precisa y deliberada como lo hizo esta ley, resguardan indicios -mediados por los periódicos, no hay que olvidarlo- de cómo los propios trabajadores entendían y nombraban a su mundo laboral. Se refirieron a él con un abanico de expresiones afines entre sí: "servicio relativo a una casa", "gobierno de una casa", "destino doméstico", "ocupación doméstica", "ejercicio doméstico de una casa", "destino [...] de cualquier clase doméstica", "cuidar de una casa", "acomodarse en casa particular", "servir". ${ }^{2}$ Todas estas variantes comprendían un conjunto de actividades específicas ligadas al cuidado, aseo y aprovisionamiento del espacio doméstico y sus integrantes, que por entonces no se circunscribía sólo a las viviendas familiares, también comprendía otros lugares en donde se hacía vida en comunidad, como conventos, hospicios y colegios. A quienes las realizaban se les llamaba "sirviente(a)",

${ }^{52}$ Diario de México, 26 de julio de 1806, p. 346; 23 de abril de 1807, p. 5503; 3 de abril de 1808 , p. 276; 23 de junio de 1810, p. 702. El Sol, 6 de julio de 1823 de 1823, p. 8827; 27 abril de 1824 , p. 1272; 14 de agosto de 1824, p. 244; 9 de junio de 1827, p. 3001; 11 de abril de 1828, p. $6038 ; 9$ de mayo de 1828, p. 7050; 24 de julio de 1828, p. 7354; 1 de julio de 1829, p. 4; 20 de enero de 1830 , p. 816 . 
"criado(a)" "doméstico(a)" o "mozo(a)", ${ }^{53}$ denominaciones equivalentes que se utilizaban indistintamente para englobar y diferenciar a estos trabajadores diestros en labores no calificadas - "mecánicas", decía la ley- de quienes sí practicaban oficios calificados, como artesanos en talleres y obrajes, así como de los capacitados en el saber especializado de la escritura, entre ellos, escribanos, preceptores y algunos dependientes de comercios.

Aunque algunos anunciantes se nombraron a sí mismos con esos términos genéricos, sabían que no eran rígidos, pues en la práctica cotidiana el servicio doméstico no era homogéneo, sino compuesto internamente por una clara división del trabajo. De modo tal que la mayoría solicitó laborar como sirvientes, pero además distinguieron, con base en sus preferencias y aspiraciones personales, los oficios que estaban dispuestos a realizar, así como aquellos que rechazaban. ${ }^{54}$ Este acto de elección puede rastrearse conociendo las actividades laborales mencionadas en cada anuncio, y cuántas de ellas fueron seleccionadas por cada trabajador para su desempeño. El cuadro 1 muestra en números absolutos que entre 64 y $67 \%$ del total de sirvientes pidió trabajo para realizar un oficio en particular, mientras que de 20 a $23 \%$ manifestó preferencia por dos diferentes y, finalmente, cerca de $13 \%$ se mostró dispuesto a emplearse en tres o más. Esta tendencia es la misma si se analiza por separado el trabajo femenino y el masculino, aunque los porcentajes en cada grupo varían. Es de resaltar que, si bien en ambos géneros la mayoría no fue indiferente a realizar cualquier oficio, el porcentaje de mujeres que mencionó solamente uno (75.8-76.26 \%) es aproximadamente $20 \%$ mayor que el de los hombres (53.9-56.53\%), lo que indica que las primeras fueron más selectivas cuando optaron por emplearse.

${ }^{53}$ El uso indistinto de estos términos se puede apreciar en algunas expresiones: "criado general para todo cuando necesite una familia", "criado doméstico", "mozo [...] muy útil para el servicio de una casa", "mozo de casa particular". Diario de México, 19 de julio de 1806, p. 328; 26 de julio de 1806, p. 346; 25 de agosto de 1806, p. 476; 15 de septiembre de 1806, p. 64; 10 de noviembre de 1806, p. 293; 8 de marzo de 1807, p. 264; 23 de abril de 1807, p. 550; El Sol, 18 de abril de 1828, p. 6066; 20 de abril de 1828, p. 6074; 26 de julio de 1828, p. 7362; 23 de octubre de 1828, p. 7718; 17 de noviembre de 1828, p. 7818; 16 de enero de 1832, p. 3760; 4 de septiembre de 1832, p. 4496; 12 de abril de 1828, p. 6042; 25 de agosto de 1829, p. 224; 11 de mayo de 1826 , p. 1328.

54 "En la calle del Relox, núm. 10, casa de la rejita, primer patio, cuarto que está junto a la escalera, darán razón de un sujeto que lo solicita de lo que se proporcione, excepto de cochero o lacayo", Diario de México, 8 de marzo de 1812, p. 264. También, Diario de México, 10 de mayo de 1806, p. 40; 25 de octubre de 1807, p. 506; El Sol, 14 de abril de 1826, p. 1220; 11 de enero de 1828 , p. 3872. 
Cuadro 1. Número de oficios solicitados por cada anuncio
en el Diario de México (1805-1816) y El Sol (1823-1832)

\begin{tabular}{lrrrrrc} 
& \multicolumn{2}{c}{ Mujeres } & \multicolumn{2}{c}{ Hombres } & \multicolumn{2}{c}{ Total } \\
Número de oficios & & $\%$ & & $\%$ & & $\%$ \\
& & & & & & \\
Diario de México & & & & & & \\
Un oficio & 302 & 76.26 & 186 & 56.53 & 488 & 67.3 \\
Dos oficios & 58 & 14.64 & 86 & 26.13 & 144 & 19.8 \\
Más de dos oficios & 36 & 9.09 & 57 & 17.32 & 93 & 12.8 \\
Total & 396 & 100 & 329 & 100 & 725 & 100
\end{tabular}

El Sol

$\begin{array}{lrrrrrr}\text { Un oficio } & 94 & 75.80 & 76 & 53.90 & 170 & 64.15 \\ \text { Dos oficios } & 21 & 16.93 & 40 & 28.36 & 61 & 23.01 \\ \text { Más de dos oficios } & 9 & 7.25 & 25 & 17.73 & 34 & 12.83 \\ \text { Total } & 124 & 100 & 141 & 100 & 265 & 100\end{array}$

Fuente: elaboración propia con base en el Diario de México (1805-1816) y El Sol (1823-1832).

Una de las razones de lo anterior pudo ser que habiendo más hombres que mujeres cabeza de familia, los primeros se mantuvieron abiertos a un espectro más amplio de posibilidades laborales siempre y cuando pudieran granjear el sustento de sus parientes y el propio. Esta propensión es evidente cuando se expresaron bajo los siguientes términos: "Un sujeto hombre de bien lo solicita de portero, o cosa semejante [...]", o "Un sujeto hombre de bien solicita destino, bien de cuidar caballos o de cochero, portero o alguna otra cosa" ${ }^{55}$ Salta a la vista en los cuadros 2 y 3 que la segunda actividad con más menciones masculinas es la que hemos consignado como "de lo que se ofrezca" -con baja participación femenina-, para englobar una serie de expresiones que denotaban la voluntad de encontrar un empleo por encima de cualquier preferencia en un oficio específico: "cualquier cosa que se ofrezca", "cualquier destino", "cosa semejante", "cualquier otra cosa", "destino [que] sea de lo que fuere". Aunque imprecisas, hemos cuantificado estas alusiones porque la mayoría de las veces aparecieron como segunda o tercera opción,

${ }_{55}$ Diario de México, 6 de mayo de 1811, p. 516; El Sol, 15 de febrero de 1827, p. 2446. 


\section{Cuadro 2. Oficios solicitados en el Diario de México, 1805-1816}

\begin{tabular}{|c|c|c|c|c|c|}
\hline \multicolumn{4}{|c|}{ Mujeres } & \multicolumn{2}{|c|}{ Hombres } \\
\hline & \multicolumn{2}{|c|}{ Menciones } & \multirow[b]{2}{*}{ Oficios } & \multicolumn{2}{|c|}{ Menciones } \\
\hline Oficios & Total & $\%$ & & Total & $\%$ \\
\hline Chichigua/nodriza & 96 & 21.52 & Portero & 172 & 32.33 \\
\hline Costurera & 83 & 18.60 & De lo que se ofrezca & 87 & 16.35 \\
\hline Recamarera & 60 & 13.45 & Mozo & 24 & 4.51 \\
\hline Ama de llaves & 47 & 10.53 & Lacayo & 23 & 4.32 \\
\hline Cuidar hombres solos & 33 & 7.39 & Paje & 23 & 4.32 \\
\hline De lo que se ofrezca & 28 & 6.27 & Giro comercial $^{\mathrm{b}}$ & 23 & 4.32 \\
\hline Cocinera & 26 & 5.82 & Criado de camino & 22 & 4.13 \\
\hline Lavandera & 18 & 4.03 & Cocinero & 22 & 4.13 \\
\hline Cuidar una familia/casa & 12 & 2.69 & Mandadero & 22 & 4.13 \\
\hline Pilmama/cuidar niños & 11 & 2.46 & Oficios de campo ${ }^{c}$ & 22 & 4.13 \\
\hline Giro comerciala & 11 & 2.46 & Ayuda de cámara & 17 & 3.19 \\
\hline Criada & 9 & 2.01 & Picador (cuidado & & \\
\hline Sirvienta & 9 & 2.01 & de caballos) & 17 & 3.19 \\
\hline Galopina & 1 & 0.22 & Otros $^{\mathrm{d}}$ & 13 & 2.44 \\
\hline Para todo & 1 & 0.22 & Sirviente & 11 & 2.06 \\
\hline Maestra de niñas & 1 & 0.22 & Cochero & 10 & 1.87 \\
\hline & & & Mayordomo de casa & 6 & 1.12 \\
\hline & & & Oficios letrados & 6 & 1.12 \\
\hline & & & Asistente personal & 4 & 0.75 \\
\hline & & & Criado & 3 & 0.56 \\
\hline & & & Ayo de niños & 3 & 0.56 \\
\hline & & & Enfermero & 2 & 0.37 \\
\hline Total & 446 & 100 & Total & 532 & 100 \\
\hline
\end{tabular}

a Incluye bizcochería, chocolatería, velería, confitería, estanquillo, "casa de trato", hacer dulces.

${ }^{\mathrm{b}}$ Incluye tendero, cajero, dependiente de botica, dependiente de tienda, mayordomo de tocinería, mayordomo de panadería, cuidar oficina.

' Incluye administrador de hacienda, dependiente de hacienda, trojero, caporal, caballerango, mozo de campo.

${ }^{d}$ Incluye sobrestante, sacristán, recaudador de dinero, arrendador.

${ }^{\mathrm{e}}$ Incluye escribiente, amanuense, enseñanza de primeras letras, enseñanza de niños.

Fuente: elaboración propia con base en el Diario de México, 1805-1816. 
Cuadro 3. Oficios solicitados en El Sol (1823-1832)

\begin{tabular}{|c|c|c|c|c|c|}
\hline \multirow[b]{3}{*}{ Oficios } & \multicolumn{2}{|c|}{ Mujeres } & \multirow[b]{3}{*}{ Oficios } & \multicolumn{2}{|c|}{ Hombres } \\
\hline & \multicolumn{2}{|c|}{ Menciones } & & \multicolumn{2}{|c|}{ Menciones } \\
\hline & Total & $\%$ & & Total & $\%$ \\
\hline Chichigua/nodriza & 48 & 29.62 & Portero & 56 & 23.43 \\
\hline Cuidar hombres solos & 39 & 24.07 & De lo que se ofrezca & 50 & 20.92 \\
\hline Giro comercial $^{a}$ & 11 & 6.79 & Mozo & 45 & 18.82 \\
\hline Ama de llaves & 9 & 5.55 & Picador & 16 & 6.69 \\
\hline Cocinera & 9 & 5.55 & Criado de camino & 13 & 5.43 \\
\hline Recamarera & 9 & 5.55 & Sirviente & 10 & 4.18 \\
\hline Costurera & 7 & 4.32 & Cochero & 10 & 4.18 \\
\hline Cuidar una familia/casa & 7 & 4.32 & Doméstico & 9 & 3.76 \\
\hline Sirvienta & 5 & 3.08 & Criado & 8 & 3.34 \\
\hline Cuidar enfermos & 4 & 2.46 & Cocinero & 4 & 1.67 \\
\hline Pilmama/cuidar niños & 3 & 1.85 & Ayuda de cámara & 4 & 1.67 \\
\hline De lo que se ofrezca & 3 & 1.85 & Oficios de campo ${ }^{b}$ & 4 & 1.67 \\
\hline Criada & 2 & 1.23 & Giros comerciales $^{c}$ & 4 & 1.67 \\
\hline Moza & 2 & 1.23 & Oficios letrados ${ }^{\mathrm{d}}$ & 3 & 1.25 \\
\hline Lavandera & 2 & 1.23 & Cuidar hombres solos & 2 & 0.83 \\
\hline Acompañar a una señora & 2 & 1.23 & Cuidar casa & 1 & 0.41 \\
\hline Total & 162 & 100 & Total & 239 & 100 \\
\hline $\begin{array}{l}{ }^{\mathrm{a}} \text { Incluye "casa de tra } \\
{ }^{\mathrm{b}} \text { Incluye mayordon } \\
\text { aquero. } \\
{ }^{\mathrm{c}} \text { Incluye mozo de ca } \\
{ }^{\mathrm{d}} \text { Incluye "escribiente } \\
\text { Fuente: elaboración }\end{array}$ & "ca & $\begin{array}{l}\text { e come } \\
\text { enda, }\end{array}$ & $\begin{array}{l}\text { ", baño, chocolatería. } \\
\text { leado de hacienda, mi } \\
\text { e de comercio. } \\
\text { Sol, 1823-1832. }\end{array}$ & $\mathrm{cal}$ & ango, \\
\hline
\end{tabular}

después de que los anunciantes indicaron sus oficios prioritarios. "Cualquier destino" podía significar una actividad subalterna en el comercio, labores del campo o en el servicio doméstico, mostrando así que este último no era un mundo aparte de cualquier otra forma de empleo. Antes bien, los trabajadores podían entrar y salir de él repetidamente a lo largo de sus vidas sin problema alguno, según las condiciones del mercado laboral en determinado momento, lo que revela lo fronterizo y contingente de esta actividad, rasgo 
ignorado por la ley antes citada, misma que trazó una división tajante entre el trabajo urbano y el rural. En todo caso, es probable que esos otros destinos no especificados se trataran de empleo no calificado, pues las menciones a oficios artesanales, como segunda o tercera opción en las preferencias, fueron prácticamente inexistentes, mientras que las actividades letradas $(1.12 \mathrm{y}$ $1.25 \%$ ) o en giros comerciales ( 4.32 y $1.67 \%$ ) no alcanzaron cifras relevantes.

La actividad masculina más solicitada fue la de portero (32.33\% de las menciones en el Diario y $23.43 \%$ en El Sol), sin duda por sus condiciones laborales. En principio, las oportunidades de empleo para ese oficio eran copiosas en comparación con otros, pues además de viviendas particulares, conventos y colegios, se requirió en edificios de gobierno y numerosos establecimientos comerciales. Asimismo, era frecuente que a los porteros se les designara un cuarto para vivir dentro de los mismos edificios que velaban, así como raciones de maíz independientes de su salario, beneficios atractivos sobre todo para aquellos que eran casados. Si bien no en todos los avisos se hace referencia al estado civil de los anunciantes, es significativo que la mayoría de quienes dijeron tener esposa, y en ocasiones también hijos, pidieron ser empleados como porteros, acaso guiados por la posibilidad de llevar consigo a sus familias, ${ }^{56} \mathrm{e}$ incluso con la intención de que ellas también fueran ocupadas como sirvientas. ${ }^{57}$ Respecto a la demanda de trabajadores, los porteros ocuparon la segunda posición en el Diario (19.56\%), sólo después de los mandaderos (34.78\%), patrón semejante en el caso de El Sol (18.88\%).

Por su parte, el trabajo femenino también presentó una diversificación de oficios, aunque es posible identificar algunas constantes entre los más solicitados. En el Diario predominaron cuatro ocupaciones: nodrizas, costureras ${ }^{58}$ recamareras y amas de llaves, que juntas alcanzan $64.1 \%$ de las

56 "Don Claudio Ávila solicita acomodo de portero de panadería o de casa. Es casado y tiene una niña grande [...]", Diario de México, 19 de enero de 1813, p. 124; "La persona que necesite de un mozo o portero, casado y sin más familia que su mujer, ocurra a la tocinería de la calle del Espíritu Santo junto al núm. 4 [...]". El Sol, 8 de enero de 1828, p. 3850. Por su parte, algunos amos permitían que se mudaran con su familia, El Sol, 14 de junio de 1826, p. 1462.

57 "Lo solicita de portero un sujeto de conducta, con la circunstancia de que a su mujer se le destine en algún ejercicio en la misma casa [...]", Diario de México, 20 de octubre de 1815, p. 424. Otros casos en Diario de México, 25 de noviembre de 1805, p. 236; El Sol, 4 de diciembre de 1824, p. 728; 29 de julio de 1827, p. 3200; 21 de agosto de 1827, p. 3292.

${ }_{58}$ Algunas de las mujeres que se dedicaban a la hechura y compostura de ropa hacían el trabajo en sus propias casas y por horas: "Lo solicita [acomodo] de costurera para ir u venir, Doña María Guzmán, vive en la calle de Arcinas número 7”, Diario de México, 8 de abril de 
menciones. Mientras que en El Sol fueron dos: nodrizas y mujeres destinadas al cuidado de "hombres solos", que suman $53.69 \%$. En los cuadros 2 y 3 se aprecia que ambos periódicos fungieron como medios muy utilizados por las mujeres para insertarse en el mercado de la lactancia asalariada, oferta de brazos que se correspondía con su demanda, pues en los cuadros 4 y 5 se lee que las chichiguas fueron las trabajadoras más solicitadas por los amos. De igual modo, la correlación entre oferta y demanda está presente en las costureras y recamareras para el caso del Diario. Las primeras representan el segundo puesto en las menciones de las trabajadoras y el tercero en los amos. Por su parte, las recamareras fueron la tercera opción ocupacional de las mujeres y la cuarta de los empleadores. El resto de las actividades no sobrepasa los porcentajes de las anteriores. Según Manuel Miño (2004), hacia 1790 en el cuartel 1 de la ciudad había 784 "empleadas domésticas", de las cuales 173 eran recamareras, constituyendo la segunda actividad más importante (171172), lo que coincide con la tendencia encontrada en el Diario. Desde luego, la relación entre ambos datos es sólo hipotética, pues sería necesario verificar si después de quince o 20 años la distribución de esa ocupación era la misma, y ampliar el área de estudio más allá de un solo cuartel.

Merece una mención el hecho de que algunas mujeres buscaban empleo para cuidar a hombres solos - con pocas solicitudes masculinas-, categoría que podría ser análoga a la de sirvienta o criada, pero es probable que en la práctica cotidiana se diferenciara de estas otras actividades en razón de la carga de trabajo, inversión de tiempo y grado de sujeción que implicaba. En primera instancia, estas mujeres querían dejar claro que no pretendían servir en núcleos domésticos compuestos por familias extensas, en donde el número de parientes era proporcional a la explotación de su mano de obra. ${ }^{59}$ Segunda, asistir a una sola persona generalmente consistía en preparar su comida y cuidar la ropa ${ }^{60}$ permitiéndoles disponer de tiempo para atender a sus propias familias, pues a menudo expresaron ser casadas o "señoras",

1807, p. 390. Otras eran parte del servicio doméstico de las familias. "Se necesita una costurera de asiento en la calle de Tiburcio número 12 [...]”, El Sol, 3 de noviembre de 1826, p. 2030.

59 "Una joven española, de buena conducta, lo solicita [acomodo] de ama de llaves, recamarera o costurera en casa particular, donde no haya niños [...]", Diario de México, 25 de octubre de 1807 , p. 250.

${ }_{60}$ "Se busca una cocinera, y que sepa lavar y planchar para el servicio de dos hombres, por el rumbo de Jonacatepec [...]”, El Sol, 5 de junio de 1831, p. 2820. También, Diario de México, 5 de agosto de 1807, p. 388; El Sol, 23 de abril de 1827, p. 2802; 19 de abril de 1828, p. 6070. 


\section{Cuadro 4. Oficios ofertados en el Diario de México, 1805-1816}

\begin{tabular}{|c|c|c|c|c|c|}
\hline \multicolumn{4}{|c|}{ Mujeres } & \multicolumn{2}{|c|}{ Hombres } \\
\hline & \multicolumn{2}{|c|}{ Menciones } & \multirow[b]{2}{*}{ Oficios } & \multicolumn{2}{|c|}{ Menciones } \\
\hline Oficios & Total & $\%$ & & Total & $\%$ \\
\hline Nodriza/chichigua & 47 & 27.01 & Mandadero & 16 & 34.78 \\
\hline Cocinera & 45 & 25.86 & Portero & 9 & 19.56 \\
\hline Costurera & 23 & 13.21 & Mozo & 8 & 17.39 \\
\hline Recamarera & 15 & 8.62 & Lacayo & 3 & 6.52 \\
\hline Cuidar niños/pilmama & 8 & 4.59 & Picador & 3 & 6.52 \\
\hline Lavandera & 8 & 4.59 & Cocinero & 2 & 4.34 \\
\hline Cuidar casa/familia & 7 & 4.02 & Ayuda de cámara & 1 & 2.17 \\
\hline Mandadera & 6 & 3.44 & Cuidar hombres solos & 1 & 2.17 \\
\hline Cuidar enfermos & 4 & 2.29 & Cochero & 1 & 2.17 \\
\hline Ama de llaves & 4 & 2.29 & Mayordomo & 1 & 2.17 \\
\hline Moza & 3 & 1.72 & Criado de camino & 1 & 2.17 \\
\hline Criada & 2 & 1.14 & & & \\
\hline Cuidar hombres solos & 2 & 1.14 & & & \\
\hline Total & 174 & 100 & Total & 46 & 100 \\
\hline
\end{tabular}

Fuente: elaboración propia con base en el Diario de México, 1805-1816.

en vez de solas o solteras como ocurrió con otros oficios, entre ellas algunas chichiguas. ${ }^{61} \mathrm{Y}$ tercera, con esta actividad podían continuar habitando sus viviendas. Si bien la relación entre amo y sirviente siempre fue jerárquica, en este caso las pretensiones de control de los primeros eran más relajadas en comparación con quienes se alojaban en casa de sus empleadores. Al ser una forma de trabajo por horas y temporal, ${ }^{62}$ es viable que fuera la opción

${ }_{61}$ "Ana Micaela, soltera, solicita acomodo de chichigua: vive en los bajos de San Juan de Dios a la accesoria 3 contigua al farol", Diario de México, 19 de octubre de 1806, p. 200; 12 de septiembre de 1813, p. 4; 1 de octubre de 1811, p. 374; El Sol, 28 de diciembre de 1829, p. 724.

${ }_{62}$ "En la calle del puente de Jesús María núm. 6 está una señora que por un tanto diario asiste a hombres solos de todo a todo", El Sol, 11 de octubre de 1826, p. 1938. Cursivas mías. 
Cuadro 5. Oficios ofertados en El Sol, 1823-1832

\begin{tabular}{lrrlrrr} 
& \multicolumn{2}{c}{$\begin{array}{c}\text { Mujeres } \\
\text { Menciones }\end{array}$} & & \multicolumn{2}{c}{ Hombres } \\
& Total & $\%$ & & \multicolumn{2}{c}{ Menciones } \\
& & & & Total & $\%$ \\
Nodrizas/chichigua & 16 & 51.61 & Cocinero & 5 & 45.45 \\
Cuidar una casa & 4 & 12.90 & Criado & 2 & 18.18 \\
Cuidar hombres solos & 2 & 6.45 & Portero & 2 & 18.18 \\
Cuidar niños & 2 & 6.45 & Cuidar hombres solos & 1 & 9.09 \\
Lavandera & 2 & 6.45 & Criado de camino & 1 & 9.09 \\
Recamarera & 2 & 6.45 & & & \\
Costurera & 2 & 6.45 & & & \\
Cocinera & 1 & 3.22 & & 11 & 99.9 \\
Total & 31 & 99.9 & Total &
\end{tabular}

Fuente: elaboración propia con base en El Sol, 1823-1832.

más adecuada para no pocas mujeres, pues significó la quinta ocupación más solicitada en el Diario (7.39\%), pero la segunda en El Sol (24.07 por ciento). ${ }^{63}$

Ahora bien, sólo algunos cuantos anunciantes consignaron su lugar de origen. Cuando lo manifestaron dijeron que provenían de "tierra dentro", Oaxaca, Guatemala, La Habana, Manila, España, Inglaterra, "Oriente”; o usaron adjetivos como "foráneo", "ranchero", "europeo" o "extranjero". Más interesante es conocer si estaban dispuestos a salir de la ciudad, con independencia de si eran oriundos o migrantes, información ausente en censos y padrones. Según el cuadro 6, 82.20\% de los anunciantes del Diario y 64.14\% de El Sol pidieron ser contratados dentro de la capital. Para 9.65 y $22.64 \%$, respectivamente, les resultaba igual si permanecían en la urbe o salían de ella, mientras que 8.13 y $20.20 \%$ solicitó acomodo en algún otro lado. La tendencia a quedarse en la urbe es común en ambos géneros, aunque los hombres mostraron mayor disposición para dejarla en comparación con las mujeres, quizá

${ }^{63}$ Existió otra modalidad en este servicio que no hemos incluido en la cuantificación, pues implicó a la vez el arrendamiento de un inmueble: "Se solicita una habitación de un par de piezas para un hombre solo, con condición de que se le asista de un todo, pagando cumplidamente", El Sol, 13 de abril de 1826, p. 1216. 
Cuadro 6. Destinos solicitados para laborar en el Diario de México (1805-1816) y El Sol (1823-1832)

\begin{tabular}{lrrrrrr} 
& \multicolumn{2}{c}{ Mujeres } & \multicolumn{2}{c}{ Hombres } & \multicolumn{2}{c}{ Total } \\
Destino solicitado & \multicolumn{2}{c}{$\%$} & & $\%$ & & $\%$ \\
& & & & & & \\
Diario de México & & & & & & \\
En la ciudad & 351 & 88.63 & 247 & 75.07 & 596 & 82.20 \\
Fuera o en la ciudad & 17 & 4.29 & 52 & 15.80 & 70 & 9.65 \\
Fuera de la ciudad & 28 & 7.07 & 30 & 9.11 & 59 & 8.13 \\
Total & 396 & 100 & 329 & 100 & 725 & 100
\end{tabular}

El Sol

$\begin{array}{lrrrrrr}\text { En la ciudad } & 92 & 74.19 & 78 & 55.31 & 170 & 64.15 \\ \text { Fuera o en la ciudad } & 16 & 12.90 & 44 & 31.20 & 60 & 22.64 \\ \text { Fuera de la ciudad } & 16 & 12.90 & 19 & 13.47 & 35 & 13.20 \\ \text { Total } & 124 & 100 & 141 & 100 & 265 & 100\end{array}$
(1823-1832).

Fuente: elaboración propia con base en el Diario de México (1805-1816) y El Sol

por la misma razón por la que estuvieron más abiertos a realizar "cualquier destino". Por otro lado, el porcentaje de quienes buscaban migrar para unos y otros aumentó en los años 1820 respecto a las dos décadas precedentes.

Dejar la ciudad no significaba en todos los casos hacerlo de manera permanente o definitiva, como sucedió con los criados de camino que andaban itinerantes asistiendo a viandantes y regresaban intermitentemente. Otros aspiraban a emigrar por periodos quizá más prolongados, pero no siempre tenían en mente un rumbo preciso. ${ }^{64}$ Por el contrario, los hombres y mujeres que solicitaban destinos fuera tenían claro a qué lugares deseaban arribar, que estribaban en ciudades y puertos importantes. El polo de atrac-

${ }^{64}$ "Una criada, que solicita servir de cocinera, recamarera, galopina, o lavandera, al mismo tiempo está pronta para salir fuera de esta ciudad, cuidando a hombres solos o con cualquier destino [...]", Diario de México, 1 de noviembre de 1805, p. 129; "Un hombre solo solicita un destino de mozo, criado o lo que se proporcione, el cual servirá no sólo dentro de México sino fuera de él, y aun también de la república si se ofreciere [...]", El Sol, 16 de noviembre de 1827, p. 3650. 
ción más fuerte era Veracruz, seguido por Jalapa, Orizaba y Puebla, sin duda debido a la demanda de servicios que a manera de arrastre producía la ruta comercial entre la ciudad de México y aquel puerto. Asimismo, hubo quienes pretendían alcanzar Guadalajara y las costas del Pacífico como Tepic y San Blas. Esporádicamente optaron por los centros mineros de Guanajuato y Querétaro, o sitios más distantes como Oaxaca, Campeche, Tampico, Durango y Monterrey.

El puerto de Veracruz era pretendido para avecindarse, pero también para embarcarse a otros destinos. Hombres y mujeres ofrecieron servir a individuos y familias que se dirigían a Europa, sólo durante el tiempo que tomaba el trayecto, o para permanecer con ellas una vez que tocaran tierra. Esta modalidad de trabajo temporal les permitía costear el viaje y emprenderlo acompañados, puesto que no siempre solicitaron el pago de un salario. ${ }^{65}$ Expresaron su deseo de emplearse con quienes iban a "Europa", principalmente a España, y en menor medida a Francia, Londres, Guatemala y La Habana ${ }^{66}$ Esta variante laboral, que empleó a niños sin la compañía de sus parientes, ${ }^{67}$ fue incentivada por dos coyunturas políticas: el traslado de individuos a propósito de las Cortes de Cádiz y la efervescencia posterior al regreso del rey, ${ }^{68}$

${ }_{65}$ "Dos señoras solicitan una familia que se vaya para España: se irán sirviendo de lo que se ofrezca sin sueldo alguno no más por costo de viaje [...]", El Sol, 2 de febrero de 1828 , p. 3960; 23 de enero de 1828, p. 3920. "Se solicita un sujeto decente y de conducta para que acompañe una familia a Veracruz al cual se le dará el asiento en el coche por sólo la compañía y que cuide que se cargue y descargue el coche [...]", El Sol, 17 de febrero de 1828, p. 4020.

${ }^{66}$ Algunos se mantuvieron dispuestos a viajar a cualquier parte del mundo: "Se solicita un acomodo para fuera de la nación o Inglaterra, Francia, Italia y demás cortes de la Europa y también para China y Lima: sabe cuidar caballos, servir y poner mesa y cuanto le manden [...]", El Sol, 31 de agosto de 1827, p. 3332.

${ }_{67}$ "Si alguna persona de las que pasan a España en el próximo convoy, quisiera llevar una niña en calidad de sirvienta, ocurra a la calle del Montón núm. 7", El Sol, 11 de octubre de 1815, p. 4. "Si alguna de las personas que salen fuera de la república necesitare de dos niñas para que le sirvan en clase de costureras o recamareras, ocurra a la plaza de San Fernando núm. 42 [...]", El Sol, 23 de enero de 1828, p. 3920.

68 "Un sujeto decente, de conducta y buena letra lo solicita de amanuense o criado doméstico en esta capital, o para afuera con alguno de los señores diputados a Cortes [...]", Diario de México, 29 de julio de 1813, p. 4. Otros casos en Diario de México, 5 de diciembre de 1813 , p. $4 ; 18$ de octubre de 1814 , p. $4 ; 21$ de octubre de 1814 , p. $4 ; 11$ de octubre de 1815 , p. $4 ; 13$ de octubre de 1815; 14 de octubre de 1815; 19 de enero de 1816, p. 4; 9 de julio de 1816, p. 4; 11 de septiembre de 1816 . 
así como la expulsión de españoles ordenada por las leyes mexicanas entre 1827 y $1829 .{ }^{69}$

\section{CONSIDERACIONES FINALES}

Los avisos de sirvientes son una oportunidad para repensar el aparente alejamiento de las clases populares respecto a la cultura escrita, como si se tratara de una realidad uniforme del siglo xix. Esta fuente reveló a un público que no era precisamente el ilustrado o letrado que ha sido estudiado por la historiografía, el cual, se ha dicho, buscaba ser partícipe, a través de los periódicos, de una opinión pública en construcción, a la luz de una "nueva cultura política" emanada del liberalismo y el republicanismo (Coudart, 2004; Delgado 2006; Martínez Domínguez, 2006; Suárez de la Torre, 2010). El contacto de los trabajadores con la prensa estuvo motivado por una razón distinta, que tenía que ver con la necesidad de encontrar un empleo. Ello no significa que carecieran de un punto de vista sobre el gobierno o la situación económica que los rodeaba; sencillamente no lo expresaron en este medio escrito. No es posible negar el papel tan destacado que los periódicos tuvieron en la configuración de la escena política, pero conviene reconocer que, al mismo tiempo, tuvieron otra función orientada a la promoción del mercado laboral, ciertamente no con el mismo empuje que recibió la primera, pero sí de trascendencia para quienes dependían de un salario para su sustento diario y a menudo eran analfabetas.

¿Hasta qué punto los hombres y mujeres que ofrecieron sus servicios a través de los anuncios son un indicativo del estado que guardaba el mercado laboral urbano? Nuestra muestra se integró de 990 trabajadores, quienes representan, ciertamente, sólo una proporción del universo de personas que buscó un acomodo en el servicio doméstico y de las que ya estaban empleadas en él. Pero no hay motivos para creer que algo diferenciaba a los primeros de estos últimos, que recurrieron sólo a recomendaciones verbales, fuera del mundo letrado en el que funcionaban los avisos. Unos y otros compartían

\footnotetext{
69 "Una señora útil para todo lo que pueda necesitarse en el manejo de una familia, solicita acomodarse con alguna familia de las que van a Europa [...]", El Sol, 10 de enero de 1828, p. 3868. Otros ejemplos en El Sol, 18 de enero de 1828, p. 3900; 23 de enero de 1828, p. 3920; 27 de enero de 1828, p. 3936; 2 de febrero de 1828, p. 3960; 16 de marzo de 1828, p. 5036.
} 
una situación de desempleo, y es probable que aspiraran a realizar los mismos oficios y bajo condiciones similares. La única diferencia radicó en que algunos adquirieron la habilidad de entrar en contacto con la prensa, debido a factores y circunstancias que los anuncios apenas registran. Consideramos así que esta fuente permite acercase al pulso que la demanda de trabajo tuvo en los despachos e imprentas de los diarios, pero también en las calles.

En ese sentido, el número de avisos que ofrecían trabajo estuvo muy lejos de alcanzar la cifra de quienes lo demandaban, cuya frecuencia, por cierto, cambió año con año; a veces presentaron un alza y otras un notorio declive. Según intentamos mostrarlo, estas variaciones fueron consecuencia de una serie de reconfiguraciones que experimentó el canal de intermediación producto de hechos políticos y de cambios en la organización interna de los proyectos periodísticos. Sin embargo, tales variaciones no significan necesariamente que disminuyera o aumentara el índice de desempleo. Nos inclinamos a creer que la sobreoferta de trabajadores visible en los anuncios fue un reflejo de lo que sucedía en el mercado laboral ligado al servicio doméstico. De ser así, la dificultad de acceder a un empleo fue una constante, incluso si se intentaba por medio de los anuncios enviados por los amos. ¿Por qué el número de estos últimos alcanzó una cifra baja (alrededor de $20 \%$ de nuestra muestra) a pesar de que algunos remitentes probablemente eran letrados o mantenían cierto contacto con los impresos? Ello pudo deberse a una auténtica contracción de la demanda de criados comparada con la disponibilidad de brazos dispuestos a ocuparse. Pero, además, es posible que gracias a esa sobreoferta los amos contrataran domésticos con relativa facilidad, sin necesidad de recurrir a otra mediación que no fueran recomendaciones orales, mientras que los trabajadores debieron explorar vías alternas como los avisos para abrirse paso entre sus pares.

La entrada al mercado laboral por medio de este mecanismo presentó algunas tendencias basadas en las preferencias de los sirvientes. Por un lado, la mayoría manifestó su deseo de ser ocupados dentro de la ciudad de México (entre siete y ocho de cada diez trabajadores) y en una actividad específica (entre seis y siete de cada diez). Los oficios femeninos más solicitados fueron los de nodriza, costurera, recamarera, ama de llaves y el de cuidar hombres solos; mientras que entre los masculinos destacaron los de portero, mozo y "de lo que se ofrezca". Por otro lado, la demanda de estos oficios encontró en algunos casos su correlación con la oferta, como sucedió con las chichiguas, costureras, recamareras y, en menor medida, porteros y mozos. Mientras que 
una divergencia más notable entre una y otra variables se identifica en las amas de llaves (mediana demanda, poca oferta) y los mandaderos (mediana demanda, alta oferta).

Para concluir, habría que decir que este mecanismo de mediación entre amos y sirvientes operó entre particulares, sin el respaldo o intervención de corporación o institución alguna. El Ayuntamiento de la ciudad tampoco buscó en ningún momento regularlo como parte de sus funciones de policía y buen gobierno. Después de todo, en un inicio los avisos no fueron foco de atención de la censura real a los impresos y, más tarde, directores y redactores constantemente apelaron a la libertad de imprenta para decidir qué contenidos incluir y qué decir en ellos. En consecuencia, la libertad de los trabajadores para emplearse por esta vía no fue vigilada ni restringida con el propósito de controlar su movilidad en la ciudad, o incluso fuera de ella, en un contexto en que al poder político le preocupó cada vez más la presencia de desempleados y "vagos" en las calles.

Los anuncios no modificaron, en general, las bases de la centenaria relación paternalista entre amos y criados, pero estos testimonios dejan entrever la alta rotación de fuerza de trabajo, quizá incentivada o reforzada por este recurso escrito que apelaba a un público-lector que no tenía rostro o dirección definidos; a través de él podían entrar en contacto dos completos desconocidos para celebrar un acuerdo laboral. Esta movilidad iba en contrasentido de las constantes pretensiones que los amos tenían de mantener la subordinación y sujeción de sus sirvientes, preocupación que no fue exclusiva de ellos. A medida que el siglo xix avanzó, el gobierno local de la ciudad creó, en distintos momentos y coyunturas políticas, mecanismos legales y policiales para acotar la rotación de estos trabajadores, considerada una amenaza contra el paternalismo de los amos y el orden social, abrogándose la facultad de regular el acceso al mercado de trabajo.

\section{LISTA DE REFERENCIAS}

Álvarez de Miranda, P. (1992). Palabras e ideas: el léxico de la ilustración temprana en España (1680-1760). Madrid: Real Academia Española.

Andrews, C. (2006). Discusiones en torno a la reforma de la constitución de 1824 durante el primer gobierno de Anastasio Bustamante (1830-1832). Historia Mexicana, LVI(1), 71-116. 
Andrews, C. (2008). Entre la espada y la Constitución: el general Anastasio Bustamante 1780-1853. Ciudad Victoria: Universidad Autónoma de Tamaulipas/H. Congreso del Estado de Tamaulipas LX Legislatura.

Arias, J. (1974). El evangelista. En Los mexicanos pintados por sí mismos (pp. 65-72), México: Porrúa.

Arnold, L. (1995). Sobre la deducción de evidencia: estratificación en un barrio de la ciudad de México, 1777-1793. Estudios de Historia Novohispana, 15, 87-111.

Arrom, S. M. (1988). Las mujeres de la ciudad de México. México: Siglo XXI.

Arrom. S. M. (2002). Protesta popular en la ciudad de México: el motín del Parián en 1828”. En S. Arrom y S. Ortoll (coords.), Revuelta en las ciudades. Políticas populares en América Latina (pp. 83-116). México: UAM-I.

Ávila, A. (2008). La presidencia de Vicente Guerrero. En W. Fowler (coord.), Gobernantes mexicanos. T. I, 1821-1910 (pp. 75-96). México: FCE.

Becerril Guzmán, E. (2015). Las voces populares en el Diario de México, 1805-1817. En R. Ríos Zúñiga y J. Leyva (coords.), Voz popular, saberes no oficiales: humor, protesta, disidencia y organización desde la escuela, la calle y los márgenes (México, siglo XIX) (pp. 341-371). México: unAm/Bonilla Artigas Editores.

Brantz, M. (1953). Mexico, lo que fue y lo que es. México: FCE.

Cavo, A. (1870). Los tres siglos de México durante el gobierno español, hasta la entrada del Ejército Trigarante, publicada con notas y suplemento de Carlos María de Bustamante. Jalapa: Imprenta de A. Ruiz.

Coudart, L. (2004). En torno al correo de lectores de El Sol (1823-1832): espacio periodístico y “opinión pública”. En C. Gómez Álvarez y M. Soto (coords.), Transición y cultura política. De la colonia al México independiente (pp. 67-107). México: unAm.

Delgado Carranco, S. (2006). Libertad de imprenta, política y educación: su planteamiento y discusión en el Diario de México, 1810-1817. México: Instituto Mora.

Di Tella, T. (1994). Política nacional y política popular, 1820-1847. México: FCE.

Dorra, R. (1997). Entre la voz y la letra. Puebla: Universidad Autónoma de Puebla/ Plaza y Valdés.

Dublán M. y Lozano, J. (1876). Legislación mexicana o colección completa de las disposiciones legislativas expedidas desde la Independencia de la República (T. 1). México: Imprenta del Comercio.

Florescano. E. (1986). Precios del maíz y crisis agrícolas en México, 1708-1810. México: Era. García Cubas, A. (1986). El libro de mis recuerdos. México: Porrúa.

González Obregón, L. (1979). La vida en México en 1810. México: Innovación.

Guedea, V. (2005). Las publicaciones periódicas durante el proceso de independencia (1808-1821). En B. Clark de Lara y E. Speckman (ed.), La República de las Letras: 
asomos a la cultura escrita del México decimonónico. Publicaciones periódicas y otros impresos (vol. 2, pp. 29-42). México: UnAm.

Heller, C. B. (1987). Viajes por México en los años de 1845-1848. México: Banco de México. Kalman, J. (2003). Escribir en la plaza. México: FCE.

Lempérière, A. (2013). Entre Dios y el rey: la república: la ciudad de México de los siglos XVI al XIX. México: FCE.

Leyva, J. (2015). Voz popular. En R. Ríos Zúñiga y J. Leyva (coords.), Voz popular, saberes no oficiales: humor, protesta, disidencia y organización desde la escuela, la calle y los márgenes (México, siglo XIX) (pp. 35-79). México: UnAM/Bonilla Artigas Editores.

Lyon, G. F. (1984). Residencia en México, 1826. Diario de una estancia en la República de México. México: FCE.

Martínez Domínguez, L. (2006). Voces del "público": los comunicados de El Sol (julio de 1829-diciembre de 1832) (Tesis de licenciatura inédita). Universidad Autónoma del Estado de Morelos, Cuernavaca.

Martínez Domínguez, L. (2010). La prensa liberal y los primeros meses de la independencia: El Sol, 1821-1822 (Tesis de maestría inédita). UnAM, México.

Martínez Luna, E. (2002). Estudio e índice onomástico del Diario de México. Primera época (1805-1812). México: unAm.

Mayer, B. (1953). México lo que fue y lo que es. México: FCE.

Miño, M. (2004). Estructura social y ocupación de la población en la ciudad de México, 1790. En M. Miño y S. Pérez Toledo (coords.), La población de la ciudad de México en 1790. Estructura social, alimentación y vivienda (pp. 147-191). México: UAM-I/ Colmex/Conacyt.

Moncada González, G. (2013). La libertad comercial: el sistema de abasto de alimentos en la ciudad de México. México: Instituto Mora.

Mühlenpfordt, E. (1993). Ensayo de una fiel descripción de la República de México. México: Banco de México.

Ong, W. J. (1987). Oralidad y escritura: tecnologías de la palabra. México: FCE.

Ortiz Escamilla, J. (1994). Insurgencia y seguridad pública en la ciudad de México, 1810-1815. En R. Hernández Franyuti (comp.), La ciudad de México en la primera mitad del siglo XIX (T. 2, pp. 95-124). México: Instituto Mora.

Ozuna Castañeda, M. y Guzmán Gutiérrez, M. E. (2001). Para que todos lean: La Sociedad de Lectura de El Pensador Mexicano. En L. Suárez de la Torre (coord.), Empresa y cultura en tinta y papel (1800-1860) (pp. 273-284). México: Instituto Mora/unAM.

Pérez Salas, M. E. (2003). Los secretos de una empresa exitosa: la imprenta de Ignacio Cumplido”. En L. Suárez de la Torre (coord.), Constructores de un cambio cultural: 
impresores-editores y libreros en la ciudad de México (1830-1855) (pp. 101-181). México: Instituto Mora.

Pérez Toledo, S. (1996). Los hijos del trabajo: los artesanos de la ciudad de México. México: UAM-I/COLMEX.

Pérez Toledo, S. (2004). Población y estructura social de la ciudad México, 1790-1842. MéXico: UAM-I/CONACYT.

Pérez Toledo, S. (2011). Trabajadores, espacio urbano y sociabilidad en la ciudad de México 1790-1867. México: UAM-I/Miguel Ángel Porrúa.

Potash, R. A. (1986). El Banco de Avío de México: el fomento de la industria 1821-1846. México: FCE.

Quiroz, E. (2005). Entre el lujo y la subsistencia: mercado, abastecimiento y precio de la carne en la ciudad de México, 1750-1812. México: Colmex/Instituto Mora.

Roldán Vera, E. (2009). Pueblo. En J. Fernández Sebastián (dir.), Diccionario político y social del mundo iberoamericano. La era de las revoluciones, 1750-1850. Iberconceptos-I (pp. 1202-1217). Madrid: Fundación Carolina/Sociedad Estatal de Conmemoraciones Culturales/Centro de Estudios Políticos y Constitucionales.

Ruiz Gaytán F. B. (1979). Un grupo trabajador no incluido en la historia laboral mexicana (trabajadoras domésticas). En E. C. Frost, M. C. Meyer y J. Zoraida Vázquez (comps.), El trabajo y los trabajadores en la historia de México (pp. 419-455). México: Colmex/University of Arizona Press.

Salazar, F. (1987). Los sirvientes domésticos y sus amos en la ciudad de México, siglo XIX. (Tesis de licenciatura inédita). enAH, México.

Sarasúa, C. (1994). Criados, nodrizas y amos. El servicio doméstico en la formación del mercado de trabajo madrileño, 1758-1868. Madrid: Siglo XXI.

Sartorius, C. C. (1990). México hacia 1850. México: ConAculta.

Scardaville, M. C. (2004). Trabajadores, grupo doméstico y supervivencia durante el periodo colonial tardío en la ciudad de México, o "la familia pequeña no vive mejor”. En M. Miño y S. Pérez Toledo (coords.), La población de la ciudad de México en 1790. Estructura social, alimentación y vivienda (pp. 227-279). México: UAM-I/ Colmex/Conacyt.

Seed, P. (1982). Social Dimension of Race: Mexico City, 1753. Hispanic American Historical Review, 62(4), 568-596.

Suárez de la Torre, L. (2010). Prólogo. En L. Suárez de la Torre (coord.). Creación de estados de opinión en el proceso de independencia mexicana (1808-1823) (pp. 7-18). México: Instituto Mora. 
Suárez Rivera, M. (2015). El periodismo en construcción. Estrategias comerciales de la Gazeta de México, 1784-1785. Relaciones. Estudios de Historia y Sociedad, 143, 207-231.

Tanck de Estrada, D. (1999). Pueblos de indios y educación en el México colonial, 1750-1821. México: Colmex.

Vázquez Semadeni, M. E. (2010). La formación de una cultura política republicana: el debate público sobre la masonería en México, 1821-1830. México: UNAM/Colmich.

Villavicencio, F. (2010). Entre una realidad plurilingüe y un anhelo de nación. Apuntes para un estudio sociolingüístico del siglo xix. En R. Barriga Villanueva y P. Martín Butragueño (dirs.), Historia sociolingüística de México (vol. 2, pp. 713-793). México: Colmex.

Warren R. (2001). Vagrants and citizens. Politics and the masses in Mexico City from Colony to Republic. Wilmington: Scholarly Resources.

Zavala, S. (1987). El servicio personal de los indios en la Nueva España, 1576-1599 (t. 3). México: Colmex/El Colegio Nacional.

Zavala, S. (1995). El servicio personal de los indios en la Nueva España, 1700-1821 (t. 7). México: Colmex/El Colegio Nacional.

\section{HEMEROGRAFÍA}

Águila Mexicana.

Correo de la Federación.

Diario del Gobierno de la República Mexicana.

Diario de México.

El Atleta.

El Monitor Republicano.

El Republicano.

Gaceta Diaria de México.

Gazeta de México.

La Lima de Vulcano.

Noticioso General. 